\title{
Ontogeny of in situ behaviours relevant to dispersal and population connectivity in larvae of coral-reef fishes
}

\author{
Jeffrey M. Leis*, Amanda C. Hay, Greer J. Howarth \\ Ichthyology, Australian Museum, 6 College St, Sydney, New South Wales 2010, Australia
}

\begin{abstract}
Behaviour during the pelagic larval stage of coral-reef fishes can strongly influence dispersal, yet little is known of behavioural ontogeny. Speed, orientation and vertical distribution of larvae of 4 coral-reef fishes (Platax teira, Ephippidae; Lutjanus malabaricus, Lutjanidae; Epinephelus coioides, E. fuscoguttatus, Serranidae; 6 to $23 \mathrm{~mm}$ ) were measured in situ off Taiwan. In E. coioides and E. fuscoguttatus, speed was 2 to $30 \mathrm{~cm} \mathrm{~s}^{-1}$ (4 to 19 body lengths $\mathrm{s}^{-1}, \mathrm{BL} \mathrm{s}^{-1}$ ), and increased at 1.4 to $2.3 \mathrm{~cm} \mathrm{~s}^{-1} \mathrm{~mm}^{-1}$. In P. teira and L. malabaricus, speed was 11.2 to $16.6 \mathrm{~cm} \mathrm{~s}^{-1}\left(4\right.$ to $\left.20 \mathrm{BL} \mathrm{s}{ }^{-1}\right)$ across the size range. All but the smallest, slowest larvae had Reynolds numbers $>1000$, and so swam in an inertial environment. In situ speeds were 39 to $87 \%$ of critical speeds, and smaller larvae swam nearer to critical speed than larger larvae. Of the larvae 71 to $90 \%$ swam directionally, but neither percentage of directional individuals nor orientation precision increased with size. P. teira swam toward the southwest (offshore). Epinephelus species undertook ontogenetic changes in orientation. Neither orientation nor ontogenetic changes were found in L. malabaricus. Horizontal swimming can influence dispersal directly. Vertical distribution, which differed among species, can influence dispersal indirectly. P. teira became surface orientated, ascending $0.8 \mathrm{~m}$ per $\mathrm{mm}$ increase in length. L. malabaricus descended $0.5 \mathrm{~m}$ per $\mathrm{mm}$ increase in length. E. coioides ascended $0.4 \mathrm{~m}$ per $\mathrm{mm}$ increase in length. E. fuscoguttatus preferred greater depths, and lacked ontogenetic changes. The behaviours and their development show these larval reef fishes can influence dispersal in speciesspecific ways.
\end{abstract}

KEY WORDS: Connectivity - Dispersal - Larva - Ontogeny - Development - Coral reef - Fish · Serranidae $\cdot$ Lutjanidae $\cdot$ Ephippidae

\section{INTRODUCTION}

Unlike terrestrial vertebrates, the large majority of marine teleost fishes have a 2-phase life history, including a larval stage that is small and pelagic and therefore subject to dispersal in ambient currents (Cowen 2002, Fuiman \& Werner 2002). Particularly in reef fishes, adults are relatively site attached, so it is during the pelagic larval stage that the spatial scale of dispersal is determined, and this largely determines the spatial scale of population connectivity (Sale 1991, Cowen 2002). Increasing interest in estimating population connectivity in reef-fish populations comes from a desire to understand the geographic scales over which their population demography operates, from both theoretical and applied perspectives (Cowen et al. 2007, Gaines et al. 2007). One prominent means by which the scale of dispersal is estimated is by the use of numerical dispersal models (Werner et al. 2007).

Until recently, most marine ecologists assumed that dispersal of fish larvae was largely a physical process in which the behaviour of larvae played little part. Dispersal models reflected the assumption that dispersal took place over very large spatial scales (Roberts 1997). Over the past $10 \mathrm{yr}$, increasing evidence has accumulated that local self-recruitment is common and that the spatial scale of larval dispersal in reef fishes is smaller than previously assumed 
(Swearer et al. 2002, Almany et al. 2007). It is now generally recognized that larval reef fishes have behavioural capabilities that can influence dispersal outcomes, but this view is based largely on research on settlement-stage larvae at the end of their pelagic stage (Leis 2006). Little is known about the behavioural capabilities of younger, smaller larvae; yet, this information is needed to develop realistic dispersal models (Leis 2007).

Although it is widely accepted that vertical distribution behaviour (swimming and orientation) of fish larvae can strongly influence dispersal, albeit indirectly, the development of behaviours that can directly influence dispersal during the pelagic larval stage has received little attention (Leis 2006). In part, this is because, until recently, it was thought that horizontal swimming and orientation capabilities of fish larvae were too limited to directly influence dispersal outcomes. Secondly, these behaviours are difficult to observe in the sea, laboratory observations of such behaviours have tended to indicate that they were feeble, and some laboratory observations are difficult to apply to field situations. Finally, it has been widely, if implicitly, assumed that the limited behavioural capabilities of a few well-studied species (typically, of the orders Clupeiformes, Pleuronectiformes and Gadiformes) were representative of fish larvae in general (Blaxter 1986, Miller et al. 1988).

Recent work on the behaviour of reef-fish larvae has focused on larvae that are at the end of their pelagic stage and ready to settle. Settlement-stage larvae can be captured in good condition using light traps or crest nets, but younger, smaller larvae are rarely captured using these methods, and small larvae captured in towed nets are seldom in good condition. Therefore, we obtained larvae of a range of developmental stages from the aquaculture industry in Taiwan, where many species of reef fishes are commercially cultured (Yu 2002). This enabled us to study the ontogeny of behaviour in 4 commercially important reef-fish species. A previous paper (Leis et al. 2007a) reported on the ontogeny of a laboratory-based measure of swimming performance, critical speed $\left(U_{\text {crit }}\right)$. Critical speed is a valuable comparative measure of potential swimming speed, but neither larvae nor adults actually swim at their critical speed in the sea (Fulton 2007, Fisher \&
Leis 2009), although there is frequently a correlation between critical speed and in situ speed (Leis \& Fisher 2006, Leis et al. 2006a,b, Fulton 2007). We released and observed reared larvae from 4 reef-fish species of 3 families in the ocean and studied the development of swimming speed, orientation and vertical distribution, all of which are relevant to dispersal. The studied species were a batfish Platax teira (Ephippidae), a tropical snapper Lutjanus malabaricus (Lutjanidae), and 2 groupers Epinephelus coioides and E. fuscoguttatus (Serranidae). All spawn pelagic eggs that hatch in about $24 \mathrm{~h}$, and the larvae are pelagic for 3 to $5 \mathrm{wk}$ before settling into demersal habitat (Table 1), but their larvae vary in morphology (Fig. 1) from deep-bodied and robust to moderate in depth and compressed with very long spines in dorsal and pelvic fins (Leis \& Carson-Ewart 2004).

In our study of swimming, orientation and vertical distribution of larval reef fishes in the ocean, we found species-specific behavioural ontogeny. All 4 species had behaviours over the size ranges we studied that were capable of influencing dispersal outcomes.

\section{MATERIALS AND METHODS}

Larvae. Larvae were obtained from commercial aquaculture farms near Kaohsiung, Taiwan, in May 2004 and May/June 2005. Platax teira and Lutjanus malabaricus were reared in outdoor earth ponds. Epinephelus coioides and E. fuscoguttatus were reared in indoor concrete tanks. The aquaculturists did not maintain breeding stock, but obtained eggs for rearing from elsewhere. The species were identified by the farmers with reference to photographs, and we subsequently confirmed identification by examination of preserved specimens, and, for the Lutjanus species, also mitochondrial DNA. The larvae were held at the National Museum of Marine Biology and Aquarium (NMMBA), Pingtung, Taiwan, in $40 \mathrm{l}$ aquaria filled from the NMMBA seawater system and kept at ca. $25^{\circ} \mathrm{C}$. Twice daily, the larvae were fed with live, newly hatched brine shrimp Artemia sp. nauplii and $50 \%$ of the water was exchanged with fresh seawater. The bottoms of the aquaria were cleaned daily by suction.

Table 1. Characteristics of the study species, numbers of larvae and days of observation

\begin{tabular}{|c|c|c|c|c|c|}
\hline Taxon & Adult habitat & $\begin{array}{l}\text { Settlement size } \\
\quad(\mathrm{SL}, \mathrm{mm})\end{array}$ & (n) & $\begin{array}{l}\text { Larvae observed- } \\
\text { (size range, } \mathrm{SL}, \mathrm{mm})\end{array}$ & $\begin{array}{l}\text { Days of ob- } \\
\text { servation (n) }\end{array}$ \\
\hline Platax teira & Coral reefs & 30 & 11 & $6-10$ & 2 \\
\hline Lutjanus malabaricus & Low-relief reefs and banks & 25 & 32 & $12-23$ & 4 \\
\hline Epinephelus coioides & Inshore coral reefs and estuaries & $20-24$ & 33 & $9-21$ & 5 \\
\hline Epinephelus fuscoguttatus & Coral reefs & $20-24$ & 26 & $13-21$ & 2 \\
\hline
\end{tabular}




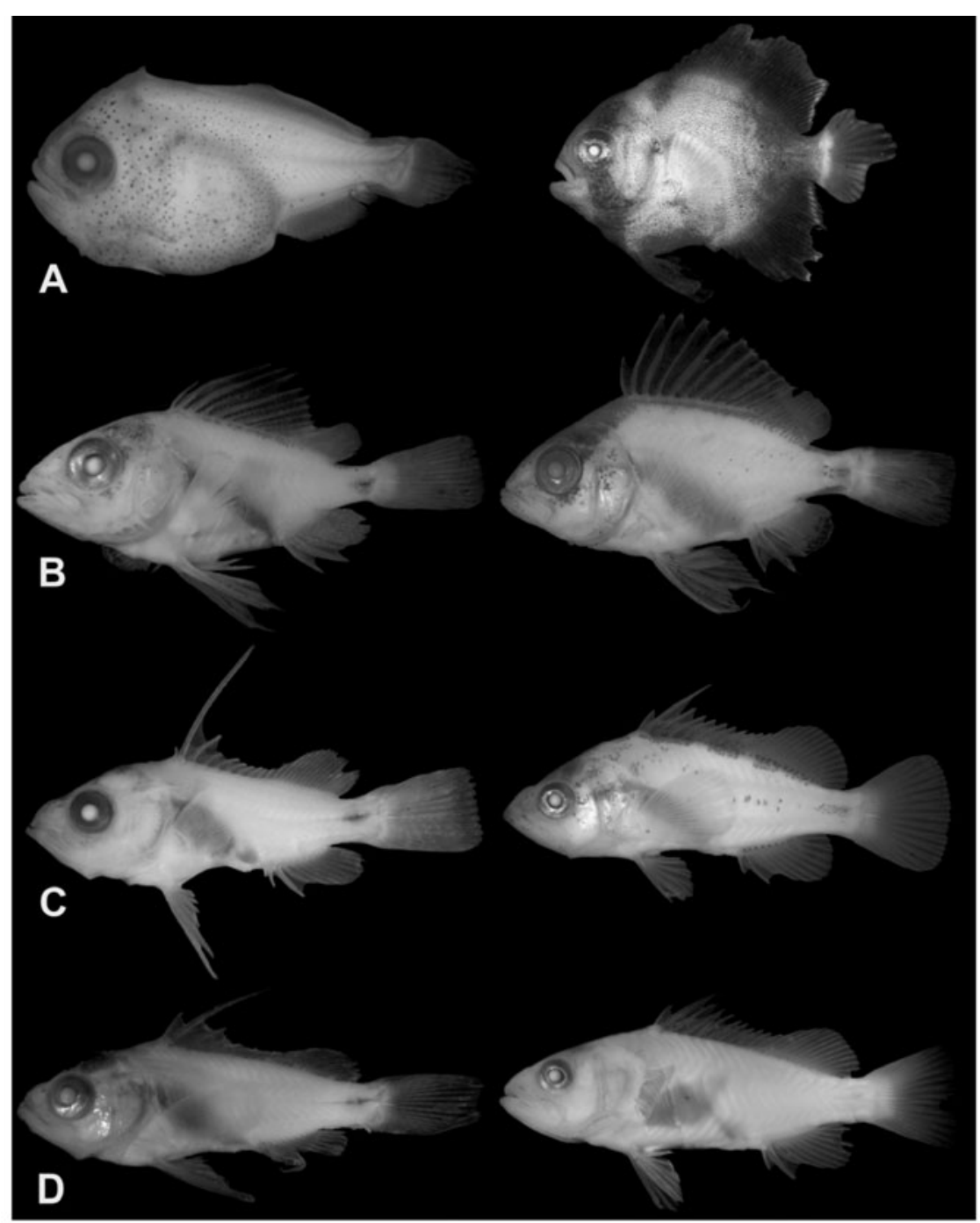

Fig. 1. Larvae of the 4 studied species over the range of sizes and developmental stages used in this research. For each species, ethanol-preserved individuals near the extremes of their size ranges (given as standard length, SL) studied are illustrated: left column, small larva and right column, large larva. The images, by M. M. Lockett and A. C. Hay, are not to scale. (A) Platax teira (Ephippidae): left, $5 \mathrm{~mm}$; right, $11 \mathrm{~mm}$. (B) Lutjanus malabaricus (Lutjanidae): left, $12.4 \mathrm{~mm}$; right, $18.5 \mathrm{~mm}$; (C) Epinephelus coioides (Serranidae): left, $9 \mathrm{~mm}$; right, $20 \mathrm{~mm}$; (D) Epinephelus fuscoguttatus (Serranidae): left, $12 \mathrm{~mm}$; right, $20 \mathrm{~mm}$

Larvae were transported from NMMBA to the study sites in covered buckets fitted with a battery-operated aerator. At the study site, seawater was gradually added to the bucket to acclimatise the larvae to ambient water conditions, and $50 \%$ of the water in the bucket was exchanged every hour. Larvae were used for observations in the morning to early afternoon, within $6 \mathrm{~h}$ of departure from NMMBA.

Reported sizes of larvae are standard length (SL, in $\mathrm{mm}$ ). The nomenclature of early-life history stages of fishes is complex, with several systems of terminology and no consensus on the most appropriate. Depending on the nomenclature used, the individuals we studied (Fig. 1) could be considered larvae, postlarvae, or juveniles, or a mixture. We did not attempt to distinguish between larvae and juveniles, and, for simplicity, we refer to the young fish under study here as larvae, but acknowledge that some terminologies might refer to them by other labels. The key point is that these small fishes were still pelagic, having not yet settled.

Field procedure. The behaviour of the larvae was observed following standard in situ procedures (Leis et al. 1996, Leis \& Carson-Ewart 1997, 1998). The size of each larva was estimated with the aid of a ruler before release. An observer diver released a larva at $5 \mathrm{~m}$ depth. The direction the observer faced when releasing the larva was randomized. Once the larva chose its initial trajectory, the observer followed the larva while a second diver followed the observer, recording data. The larvae were clearly aware of the presence of the 
divers, and behaviour of the larvae might have been influenced by the divers, but circumstantial evidence indicates that the behaviours observed were not unduly affected, and that this approach offers the best currently available means of observing the behaviour of fish larvae in the sea (Leis et al. 1996, Leis \& CarsonEwart 1997, 1998). A larva was used only once, and, where possible, was recaptured at the end of the observation period. Recaptured larvae were euthanized, fixed in ethanol, measured, and used to generate a correction factor for the pre-release size estimates of larvae not recaptured. Recaptured larvae were lodged in the Australian Museum, Sydney.

We attempted to observe each larva for $10 \mathrm{~min}$, taking measurements of swimming depth and direction with a dive computer and compass, respectively, every $30 \mathrm{~s}$. Speed was calculated from distance travelled measured by a calibrated flow meter over the full time of observation (Leis \& Carson-Ewart 1997). Thus, we measured larval speed and direction (i.e. velocity) relative to a water column that was moving, not velocity relative to the bottom. Larvae were not followed deeper than 15 to $20 \mathrm{~m}$ (depending on the dive) for safety reasons, so observations on some individuals were curtailed. Depth amplitude is the difference between the greatest and least depth observed for an individual.

Study areas. Our study area was in the South China Sea, off the southern tip of Taiwan (ca. $22^{\circ} \mathrm{N}, 121^{\circ} \mathrm{E}$; Fig. 2) in Nan Wan Bay, at the extreme south of the island, where the depth range was 16 to $41 \mathrm{~m}$ over largely sand bottom, but with some low-relief coralreef patches, and at Her Chen, on the west coast, just off the peninsula delineating the west side of Nan Wan Bay, at a depth range of 14 to $31 \mathrm{~m}$ over high-relief bottom, with a high proportion of coral reefs. In each area, observations were made at least $50 \mathrm{~m}$ offshore. Water temperature was 26 to $29^{\circ} \mathrm{C}$. Water-column depth was measured by the depth sounder on the support boat at the start of each larval release.

Data analysis. To determine the best predictor of performance, values of swimming speed were regressed against SL using linear, logarithmic, power and exponential models. In all cases, the linear model provided the best fit (highest $\mathrm{R}^{2}$ ), and only these relationships are reported. These relationships apply only over the size ranges of larvae we studied, and different relationships may well have been detected if we had been able to include smaller larvae, which would be expected to have weaker swimming abilities (Fisher et al. 2000, Clark et al. 2005). In some analyses, larvae were partitioned by size increments to compare behaviour at different stages of development. We attempted to place similar numbers of individuals within the different size groups, and the size groups differed among species.

All bearings are given as degrees magnetic, which is $3^{\circ} \mathrm{W}$ of true north in the study areas. The 21 observations of vertical distribution over $10 \mathrm{~min}$ for each larva may be autocorrelated, which would violate the assumptions of most statistical procedures. To test for this, autocorrelation among depth observations was determined (Statistix Version 1.0, NH Analytical Software) for each individual trajectory. Where significant autocorrelation was detected, depth observations were omitted until autocorrelation was eliminated (e.g. if autocorrelation at a lag of 1 was detected, every second depth observation was omitted from the analysis; for more details see Leis 2004, Huebert 2008). In about $13 \%$ of individuals, no significant autocorrelation was found, so all observations were used. In about $70 \%$ of the cases, significant autocorrelation was found only at

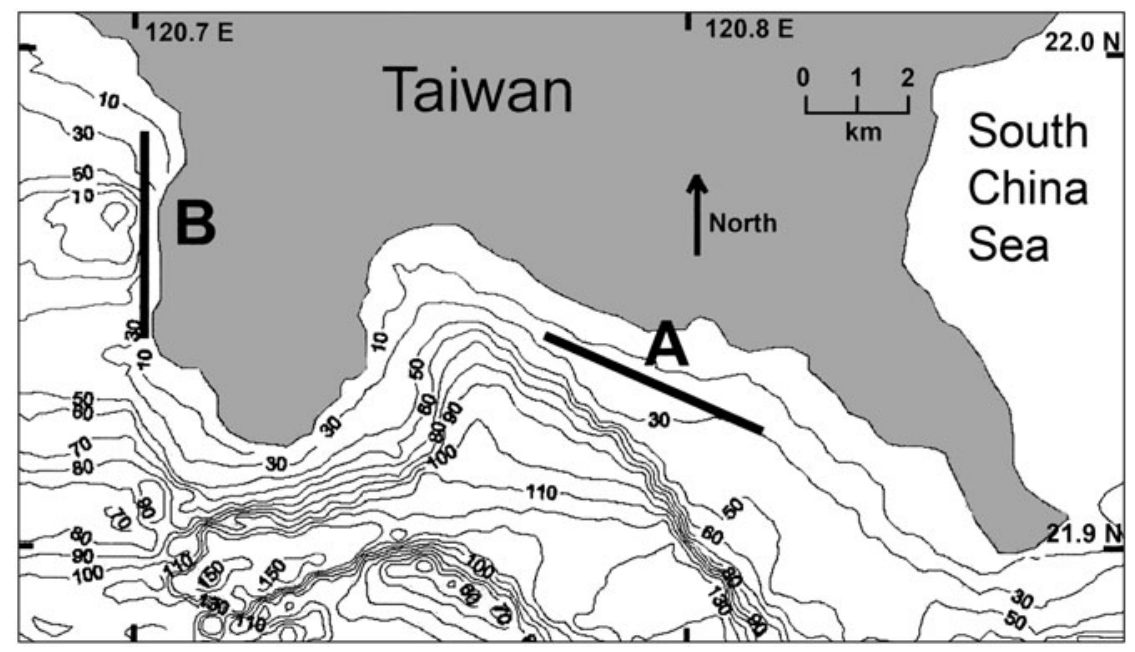

Fig. 2. Study area at the southern tip of Taiwan. Larvae were observed in situ at 2 locations: (A) in Nan Wan Bay and (B) off Her Chen on the west coast. Depth contours are in metres. Latitude and longitude in degrees are also indicated 
a lag of 1 , so only alternate observations were used. In about $17 \%$ of individuals, significant autocorrelation extended to a lag of 2, necessitating use of only every third observation. No case showed significant autocorrelation beyond a lag of 2 . Once the autocorrelation was eliminated, the remaining observations were used to construct depth-frequency distributions (proportion of observations within $2.5 \mathrm{~m}$ depth increments) for all individuals within defined size groupings. From an original total of 1764 depth observations for the 4 species, we were left with 1068 for analysis (Table 2). The depth-frequency distributions were then tested for differences among size groups of larvae by the 2-tailed, 2-sample Kolmogorov-Smirnov (K-S) test. For all statistical tests, we report actual p-values whenever possible, but consider $\mathrm{p}<0.05$ to constitute a 'significant' result.

Standard circular statistical procedures were followed for analysis of horizontal orientation data (Batschelet 1981, Zar 1996). Mean vector length ( $r$ ), is a measure of angular dispersion (or orientation precision) ranging from 0 (maximum dispersion) to 1 (lack of dispersion). The Rayleigh test (RT) was used for single-sample hypotheses about directional swimming, and the Watson-Williams (WW) test was used for multiplesample hypotheses. Rao's test was used for singlesample hypotheses if bimodality was suspected. We examined the orientation of individual larvae, and, for individuals that had significant swimming directionality, we used the individual mean bearings to examine the orientation of groups of individuals, usually selected on the basis of size. For testing distributions consisting of mean bearings of individual larvae, we included only means from individuals with non-random trajectories. Circular statistical procedures were performed with Oriana software (Version 2.01, Kovach Computing Services). In circular statistics, the terms uniform distribution and random distribution are used interchangeably (Zar 1996).

Although a total of 102 larvae of the 4 species was released and observed (Table 1), the number that provided useful data was less, as each individual did not always provide useful data of all 3 types. For example, some larvae swam downward too steeply for reliable measurement of speed, whereas other larvae were observed for too short a time $(<5 \mathrm{~min})$ to provide reliable information on orientation. As a result, 11 individuals did not provide useful speed information; 16, for orientation; and 5, for depth. When assessing differences among size-defined groups of larvae, the size range of each group was adjusted so that, within a species, the number of individuals within each group was approximately equal. This means that the number of size-defined groups, or the size range of groups, may differ among species, and in some cases within species for particular behaviours.
Table 2. Size groupings of larvae of reef-fish species and numbers of depth observations. For statistical analysis, depth observations were reduced to eliminate autocorrelation

\begin{tabular}{|llcccc|}
\hline Species & Group & $\begin{array}{c}\text { Size } \\
\text { range } \\
(\mathrm{mm})\end{array}$ & $\begin{array}{c}\text { Larvae } \\
\text { (n) }\end{array}$ & \multicolumn{2}{c|}{$\begin{array}{c}\text { Observations (n) } \\
\text { Depth }\end{array}$} \\
\hline Platax teira & Small & $6-8$ & 4 & 84 & 40 \\
& Large & $9-11$ & 7 & 117 & 83 \\
Lutjanus & Small & $12-15$ & 8 & 168 & 105 \\
malabaricus & Medium & $15-19$ & 13 & 272 & 184 \\
Epinephelus & Large & $19-23$ & 11 & 198 & 119 \\
coioides & Small & $9-12$ & 9 & 146 & 78 \\
& Medium & $13-18$ & 13 & 240 & 147 \\
Epinephelus & Large & $18-20$ & 11 & 186 & 110 \\
fuscoguttatus & Large & $18-23$ & 13 & 192 & 110 \\
\hline
\end{tabular}

\section{RESULTS}

\section{Swimming speed}

Speeds of larvae in situ ranged from 1.7 to $30.2 \mathrm{~cm}$ $\mathrm{s}^{-1}$ (Table 3). Mean speeds for each species across the sizes studied ranged from 11.2 to $20.4 \mathrm{~cm} \mathrm{~s}^{-1}$ for Platax teira and Epinephelus coioides, respectively. Although all 4 species had a positive linear relationship between swimming speed and size, only in the Epinephelus species was this relationship significant, explaining between 35 and $54 \%$ of the variation in speed (Table 3 , Fig. 3). The rate of increase in speed with increase in size was similar in the 2 Epinephelus species (1.4 to $2.3 \mathrm{~cm} \mathrm{~s}^{-1}$ per mm increase in SL, but the $95 \% \mathrm{CI}$ of the slopes broadly overlapped, Table 3).

Although the regressions in Table 3 provide the best overall representation of how speed changes across the full size range, some details are lost. Therefore, for each species, we calculated the mean $( \pm \mathrm{SE})$ speed for each $1 \mathrm{~mm}$ size increment (Fig. 4). This showed that the rotund larvae of Platax teira increased in speed rapidly with size, from about 5 to $>10 \mathrm{BL} \mathrm{s}^{-1}$ between 6 and $10 \mathrm{~mm}$ and were at least as fast as Epinephelus coioides at 9 to $10 \mathrm{~mm}$ (Fig. 4). E. coioides increased in speed at a moderate rate with increased size, and remained largely within a range of 10 to $15 \mathrm{BL} \mathrm{s}^{-1}$ throughout development. In contrast, E. fuscoguttatus was initially slow for its size $\left(<5 \mathrm{BL} \mathrm{s}^{-1}\right)$, yet increased in speed rapidly, both in terms of actual speed and standardized speed, so by $20 \mathrm{~mm}$, as it neared settlement, it swam as fast as E. coioides (both at about $12 \mathrm{BL} \mathrm{s}^{-1}$ ). The lutjanid, Lutjanus malabaricus, did not increase in speed with increased size, rather, its speed was variable, even between adjacent size classes, but with values largely between 5 and $10 \mathrm{BL} \mathrm{s}^{-1}$. 
Table 3. Ontogeny of in situ speed in larvae of 4 species of reef fishes. See Table 1 for size range of larvae, and Figs. 3 \& 4 . Model II regression (Legendre 2001) was used for in situ versus $U_{\text {crit }}$. Because $\mathrm{R}^{2}$ has no simple interpretation in Model II regression, no $\mathrm{R}^{2}$ value is provided for the in situ versus $U_{\text {crit }}$ regression formulae. SL: standard length; BL: body length; $U_{\text {crit }}$ critical speed; CI: confidence interval; SE: standard error; NS: not significant

\begin{tabular}{|c|c|c|c|c|c|c|c|}
\hline \multirow[t]{2}{*}{ Species } & \multirow{2}{*}{$\begin{array}{l}\text { Speed range } \\
\text { In situ speed } \\
\left(\mathrm{cm} \mathrm{s}^{-1}\right)\end{array}$} & \multirow{2}{*}{$\begin{array}{c}\text { Relationship } \\
\left.\text { In situ speed (cm s }{ }^{-1}\right) \\
\text { vs. SL }(\mathrm{mm})\end{array}$} & \multicolumn{5}{|c|}{ - Statistics } \\
\hline & & & $\mathrm{R}^{2}$ & $\mathrm{n}$ & $\mathrm{p}$ & $\begin{array}{c}\text { Slope } \\
95 \% \text { CI }\end{array}$ & $\begin{array}{l}\text { Mean } \mathrm{cm} \mathrm{s}^{-1} \\
\text { (SE) }\end{array}$ \\
\hline Platax teira & $3.7-20.1$ & $y=2.351 \mathrm{SL}-9.114$ & 0.279 & 11 & 0.09 (NS) & -0.49 to 5.19 & $11.20(1.72)$ \\
\hline Lutjanus malabaricus & $6.0-30.2$ & $y=0.548 \mathrm{SL}+6.634$ & 0.088 & 32 & 0.10 (NS) & -0.08 to 1.24 & $16.57(1.02)$ \\
\hline Epinephelus coioides & $5.7-30.1$ & $y=1.429 \mathrm{SL}-2.617$ & 0.538 & 29 & $<0.001$ & $0.91-1.77$ & $20.35(1.36)$ \\
\hline \multirow[t]{2}{*}{ Epinephelus fuscoguttatus } & $1.7-27.2$ & $y=2.324 \mathrm{SL}-24.98$ & 0.452 & 26 & $<0.001$ & $1.32-3.33$ & $15.86(1.65)$ \\
\hline & $\begin{array}{l}\text { In situ speed } \\
\left(\mathrm{BL} \mathrm{s}^{-1}\right)\end{array}$ & $\begin{array}{l}\text { In situ speed }\left(\mathrm{BL} \mathrm{s}^{-1}\right) \\
\text { vs. SL }(\mathrm{mm})\end{array}$ & $\mathrm{R}^{2}$ & $\mathrm{n}$ & $\mathrm{p}$ & $\begin{array}{c}\text { Slope } \\
95 \% \text { CI }\end{array}$ & $\begin{array}{l}\text { Mean BL s }{ }^{-1} \\
\quad(\mathrm{SE})\end{array}$ \\
\hline P. teira & $6.2-20.1$ & $y=1.540 \mathrm{SL}-0.693$ & 0.123 & 11 & 0.29 (NS) & 1.56 to 4.64 & $12.82(1.81)$ \\
\hline L. malabaricus & $4.2-14.8$ & $y=-0.246 \mathrm{SL}+13.700$ & 0.055 & 32 & $0.186(\mathrm{NS})$ & -6.43 to 0.12 & $9.51(0.57)$ \\
\hline E. coioides & $6.8-18.7$ & $y=0.119 S L+10.49$ & 0.015 & 29 & $0.524(\mathrm{NS})$ & -0.26 to 0.49 & $12.40(0.67)$ \\
\hline \multirow[t]{2}{*}{ E. fuscoguttatus } & $4.0-12.3$ & $y=0.704 \mathrm{SL}-3.754$ & 0.190 & 26 & 0.033 & 0.06 to 1.35 & $8.87(0.76)$ \\
\hline & In situ/U $U_{\text {crit }}$ & $\begin{array}{l}\text { In situ vs. } U_{\text {crit }} \\
\text { (both } \mathrm{cm} \mathrm{s}^{-1} \text { ) }\end{array}$ & $\mathrm{R}^{2}$ & $\mathrm{n}$ & $\mathrm{p}$ & $\begin{array}{c}\text { Slope } \\
95 \% \text { CI }\end{array}$ & $\begin{array}{c}\text { Mean in situ/ } U_{\text {crit }} \\
\text { (SE) }\end{array}$ \\
\hline P. teira & $0.49-1.16$ & $y=1.661 U_{\text {crit }}-8.182$ & - & 5 & 0.016 & 0.68 to 8.82 & $0.87(0.12)$ \\
\hline L. malabaricus & $0.32-1.40$ & $y=0.242 U_{\text {crit }}+9.030$ & - & 11 & $0.080(\mathrm{NS})$ & -0.11 to 0.66 & $0.63(0.09)$ \\
\hline E. coioides & $0.35-1.03$ & $y=0.550 U_{\text {crit }}+2.255$ & - & 8 & 0.012 & 0.19 to 1.07 & $0.67(0.07)$ \\
\hline E. fuscoguttatus & $0.14-0.80$ & $y=0.686 U_{\text {crit }}-8.031$ & - & 7 & $0.068(\mathrm{NS})$ & -0.25 to 7.86 & $0.39(0.09)$ \\
\hline
\end{tabular}
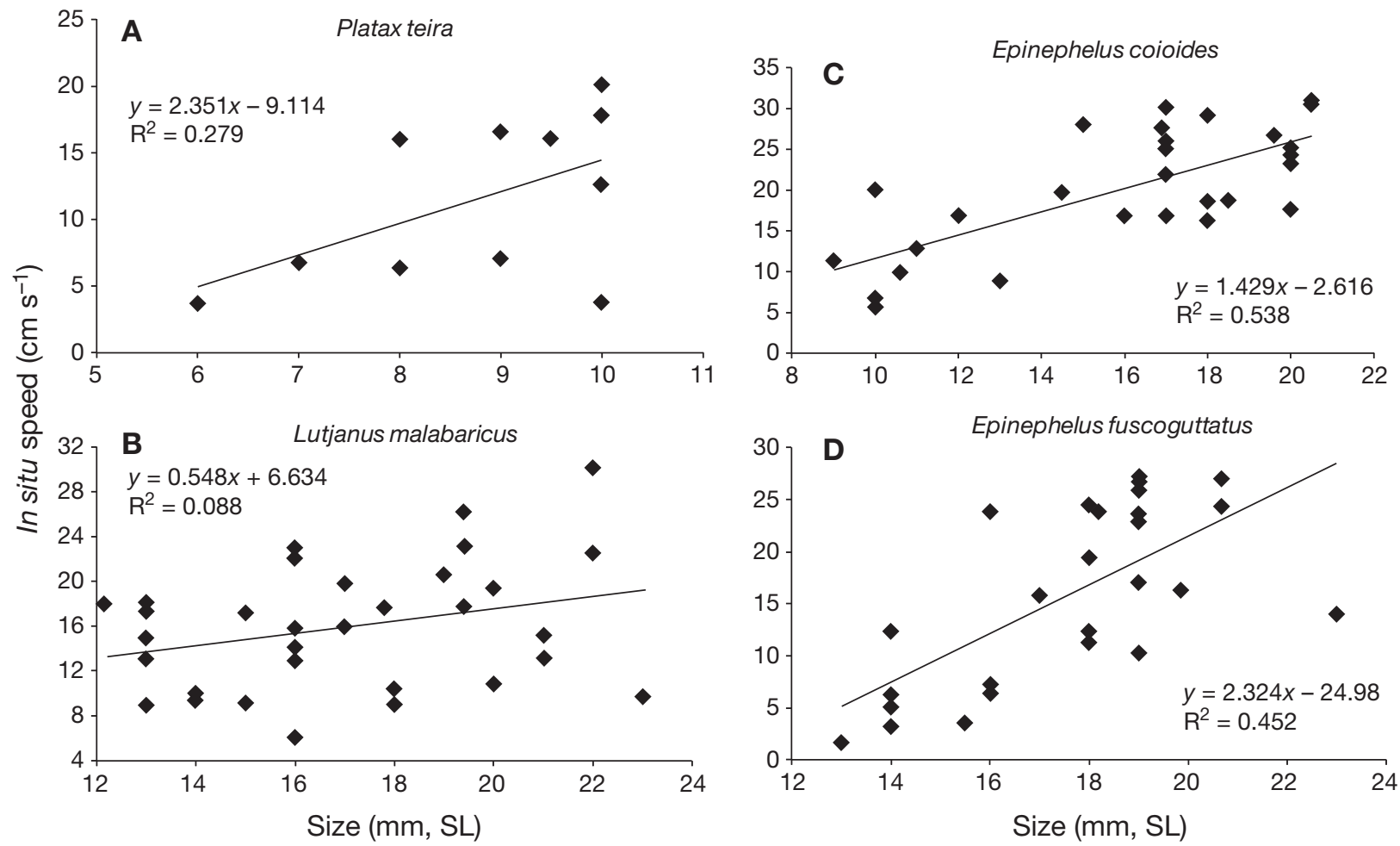

Fig. 3. Ontogeny of in situ swimming speed in larvae of 4 species of coral-reef fishes: (A) Platax teira, (B) Lutjanus malabaricus, (C) Epinephelus coioides and (D) Epinephelus fuscoguttatus. See Table 3 for details of regressions 


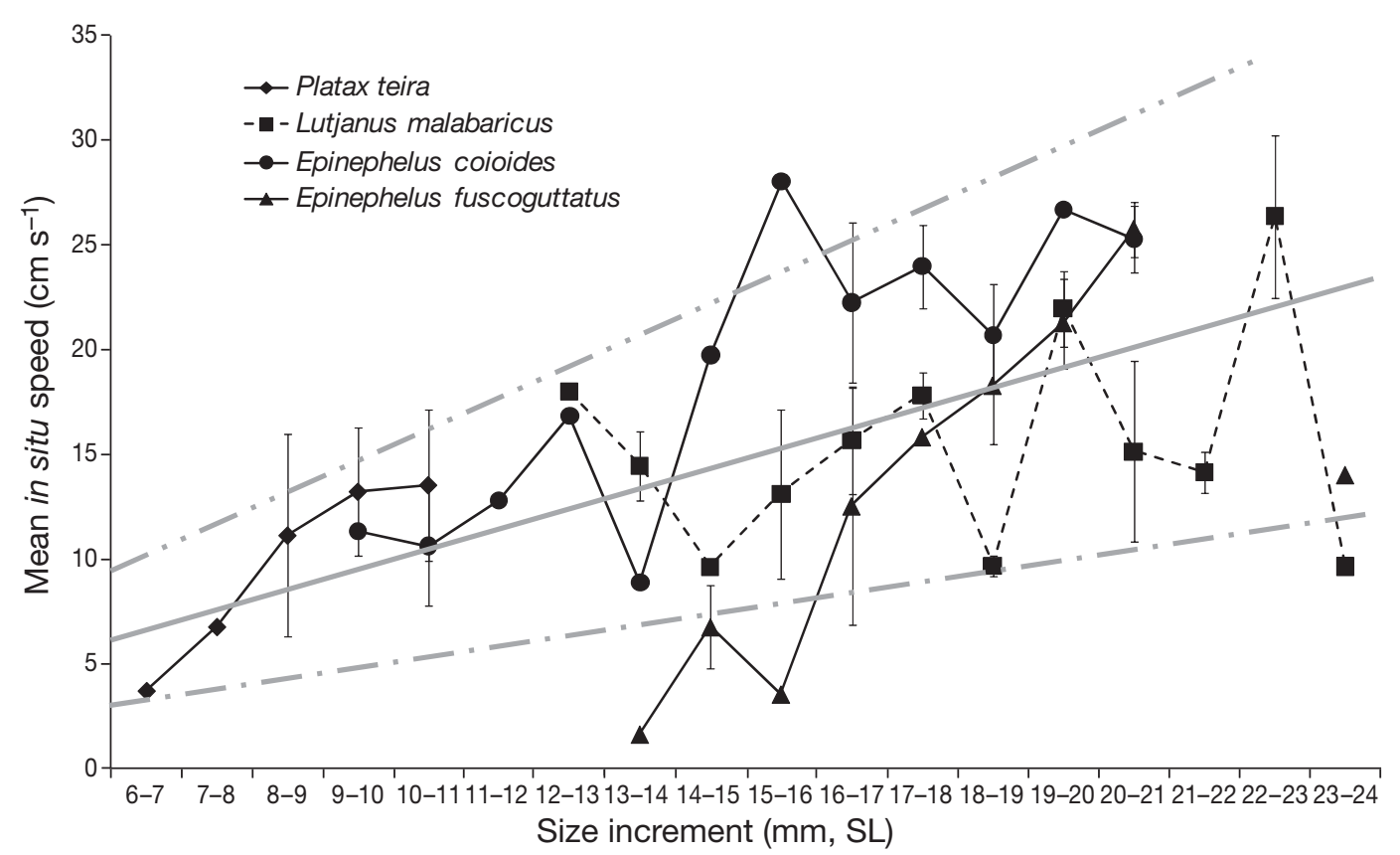

Fig. 4. Ontogeny of in situ swimming speed in larvae of 4 species of coral-reef fishes. Plotted values are mean speed $( \pm$ SE) for $1 \mathrm{~mm}$ size increments. The straight lines correspond (from top to bottom) to 15, 10 (solid line) and 5 body lengths s ${ }^{-1}$

For each species, the fastest individual within each $1 \mathrm{~mm}$ size increment was up to $11 \mathrm{~cm} \mathrm{~s}^{-1}$ faster than average (Table 4). This varied among species, with the mean difference between the fastest and average ranging from 3.2 to $6.5 \mathrm{~cm} \mathrm{~s}^{-1}$. In none of the species was the difference between best and average performance significantly related to size.

In situ speed standardized to size ranged from 4 to $20 \mathrm{BL} \mathrm{s}^{-1}$ (Table 3 ), with mean speeds for each species across the sizes studied ranging from 8.9 to $12.8 \mathrm{BL} \mathrm{s}^{-1}$ for Epinephelus fuscoguttatus and Platax teira, respectively. Standardized speed presented a variety of relationships with size, but only in the case of E. fuscoguttatus was the relationship significant; in this case, a linear relationship explained only $19 \%$ of the variation in speed (Table 3 ), i.e. an increase of $0.7 \mathrm{BL} \mathrm{s}^{-1}$ for each $1 \mathrm{~mm}$ increase in size (Fig. 4).

The Reynolds number ( $R e$; see Webb \& Weihs 1986) was calculated for each larva for which in situ speed

Table 4. Difference between fastest individual and average speed within each $1 \mathrm{~mm}$ size increment. Only increments containing $>1$ individual are included

\begin{tabular}{|lccc|}
\hline Species & $\begin{array}{c}1 \text { mm increments } \\
\text { with }>1 \text { ind. } \\
(\mathrm{n})\end{array}$ & $\begin{array}{c}\text { Mean } \\
\text { difference } \\
\left(\mathrm{cm} \mathrm{s}^{-1}\right)\end{array}$ & $\begin{array}{c}\text { Range of } \\
\text { differences } \\
\left(\mathrm{cm} \mathrm{s}^{-1}\right)\end{array}$ \\
\hline Platax teira & 3 & 4.9 & $3.3-6.6$ \\
Lutjanus malabaricus & 10 & 3.2 & $0.2-7.3$ \\
Epinephelus coioides & 7 & 6.5 & $3.9-9.4$ \\
Epinephelus fuscoguttatus & 6 & 6.1 & $1.3-11.3$ \\
\hline
\end{tabular}

was measured. Re $<300$ indicates a viscous hydrodynamic environment, whereas $\operatorname{Re}>1000$ indicates inertial forces predominate (Leis 2006). Only 1 larva had a value of $\mathrm{Re}<300$ (a $13 \mathrm{~mm}$ Epinephelus fuscoguttatus with $\mathrm{Re}=295$ ), indicting it swam in a viscous environment. In 10 larvae of 3 species (5 Platax teira, 6 to $10 \mathrm{~mm} ; 2$ E. coioides, $10 \mathrm{~mm} ; 3$ E. fuscoguttatus, 14 to $15.5 \mathrm{~mm})$, Re was between 300 and 1000, indicating an intermediate hydrodynamic environment where both inertial and viscous forces were important. The rest of the larvae $(n=87)$ had values of $\operatorname{Re}>1000$, so they were swimming in a largely inertial environment, including the smallest studied larvae of Lutjanus malabaricus (12 $\mathrm{mm}$ ) and E. coioides (9 mm). In P. teira and E. fuscoguttatus, the slowest and smallest larvae (6 to $10 \mathrm{~mm}$ and 14 to $15 \mathrm{~mm}$, respectively) swam in an intermediate environment, but a largely inertial environment was attained with a small increase in size or speed. All larvae were in a largely inertial hydrodynamic environment by 8 to $14 \mathrm{~mm}$, depending on species.

The ratio between in situ speed and critical speed (values for the latter from Leis et al. 2007a) was calculated for $1 \mathrm{~mm}$ size increments for each species, and the values ranged from 0.32 to 1.4 (Table 3, Fig. 5). The within-species mean value of this ratio ranged from 0.4 to 0.9 for Epinephelus fuscoguttatus and Platax teira, respectively. All 4 species had a positive linear relationship between in situ and critical speeds, based on the $1 \mathrm{~mm}$ increment values, but only in $P$. teira and E. coioides was this relationship significant, 

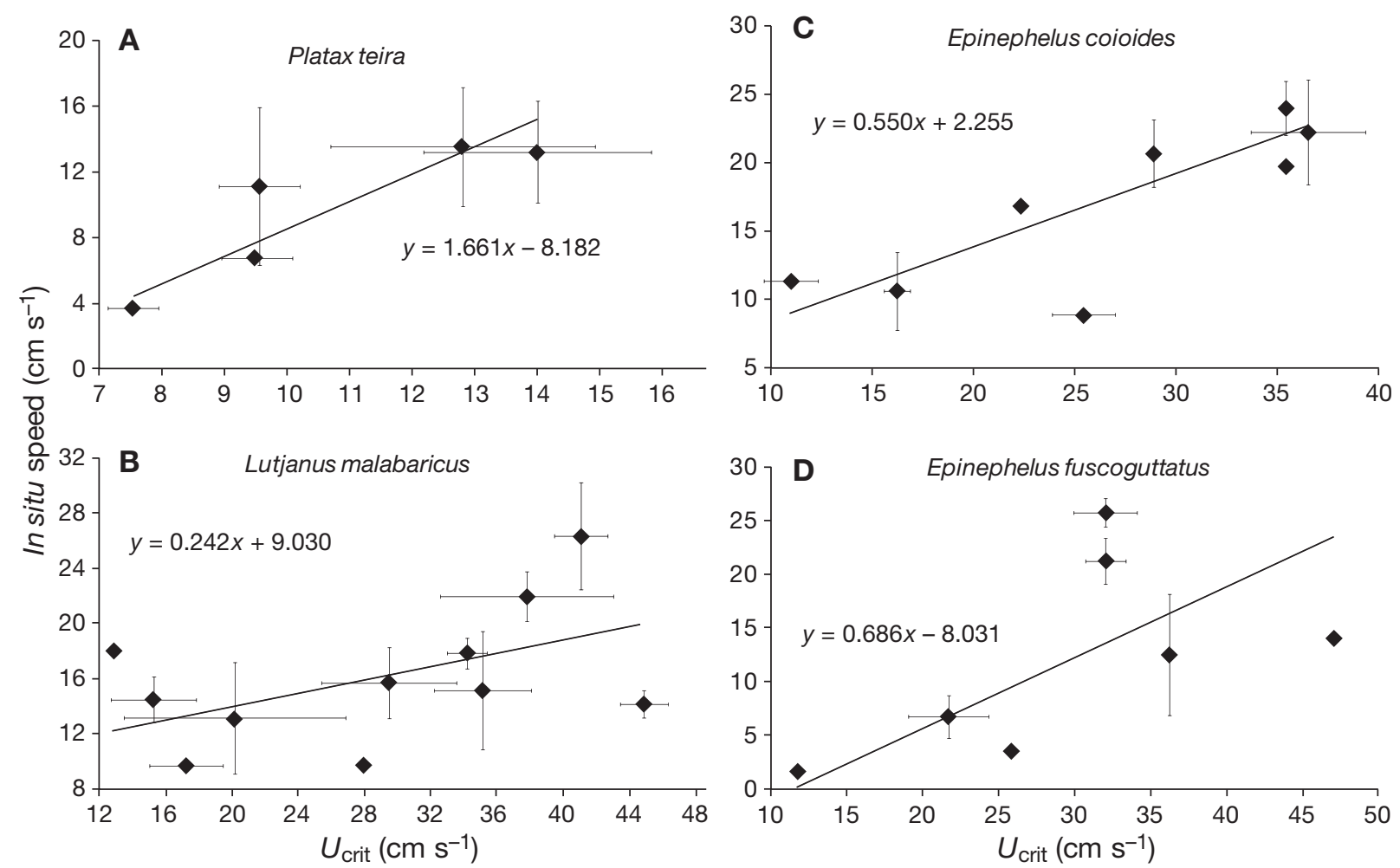

Fig. 5. Relationship of in situ speed to $U_{\text {crit }}$ in larvae of 4 species of coral-reef fishes: (A) Platax teira, (B) Lutjanus malabaricus, (C) Epinephelus coioides and (D) Epinephelus fuscoguttatus. See Table 3 for details of Model II regressions. Plotted data are means $( \pm \mathrm{SE})$ of both speed measures for $1 \mathrm{~mm}$ size increments

with critical speed explaining 79 and $65 \%$ of the variation in in situ speed, respectively (Fig. 5). Although the slopes of the relationships in these 2 species seemed disparate- 0.49 versus $1.44 \mathrm{~cm} \mathrm{~s}^{-1}$ for each $1 \mathrm{~cm} \mathrm{~s}^{-1}$ increase in critical speed - the $95 \%$ CIs for the 2 slopes broadly overlapped (Table 3 ).

\section{Orientation}

The proportion of individual larvae that had directional swimming behaviour ranged among species from 71 to $87 \%$, and the mean directional precision $(r)$ of individual larvae ranged from 0.59 to 0.66 among the 4 species (Table 5). There was no indication that precision of directionality $(r)$ changed with size of the larvae (Fig. 6), as in no species was there a significant linear relationship between size and $r$. Size explained, at most, $19 \%$ of the variation in $r$. There was no other indication of ontogenetic withinspecies trends in orientation precision (Fig. 6).
Larvae of Platax teira had strong overall directionality, swimming southwest (RT, $p=0.001$; Fig. 7), which at the study location in Nan Wan Bay was away from shore. The narrow size range ( 6 to $10 \mathrm{~mm}$ ) and small number of larvae (9 of 11 were directional) precluded any rigorous analysis of ontogenetic changes in direction, but the 2 smallest larvae ( 6 to $7 \mathrm{~mm}$ ) swam south-southeast $\left(149\right.$ to $\left.180^{\circ}\right)$, whereas the other larvae ( 8 to $10 \mathrm{~mm}$ ) swam southwest-west ( 210 to $266^{\circ}$ ).

The 27 directional larvae of Lutjanus malabaricus had an overall average swimming direction of south, but this was not significantly different from uniform

Table 5. Orientation in larvae of 4 species of coral-reef fishes. The number of individuals observed for which $>9$ bearings were made and the number (and percent) of those whose orientation was significantly different from uniform are provided. The range and mean of orientation precision $(r)$ are provided for all individuals observed. The maximum value of length of the mean vector $(r)$ is 1 , which indicates no variation in orientation by the individual

\begin{tabular}{|lccccccc|}
\hline \multirow{2}{*}{ Species } & Observed & \multicolumn{2}{c}{$\begin{array}{c}\text { Directional } \\
\text { (n) }\end{array}$} & $(\mathrm{n})$ & $(\%)$ & & \multicolumn{4}{c|}{ Range } & Mean & SE \\
\hline Platax teira & 11 & 9 & 81.8 & $0.370-0.944$ & 0.620 & 0.071 \\
Lutjanus malabaricus & 30 & 27 & 90.0 & & $0.392-0.952$ & 0.657 & 0.029 \\
Epinephelus coioides & 27 & 20 & 74.1 & $0.176-0.896$ & 0.590 & 0.045 \\
Epinephelus fuscoguttatus & 17 & 12 & 70.6 & & $0.210-0.940$ & 0.608 & 0.045 \\
\hline
\end{tabular}




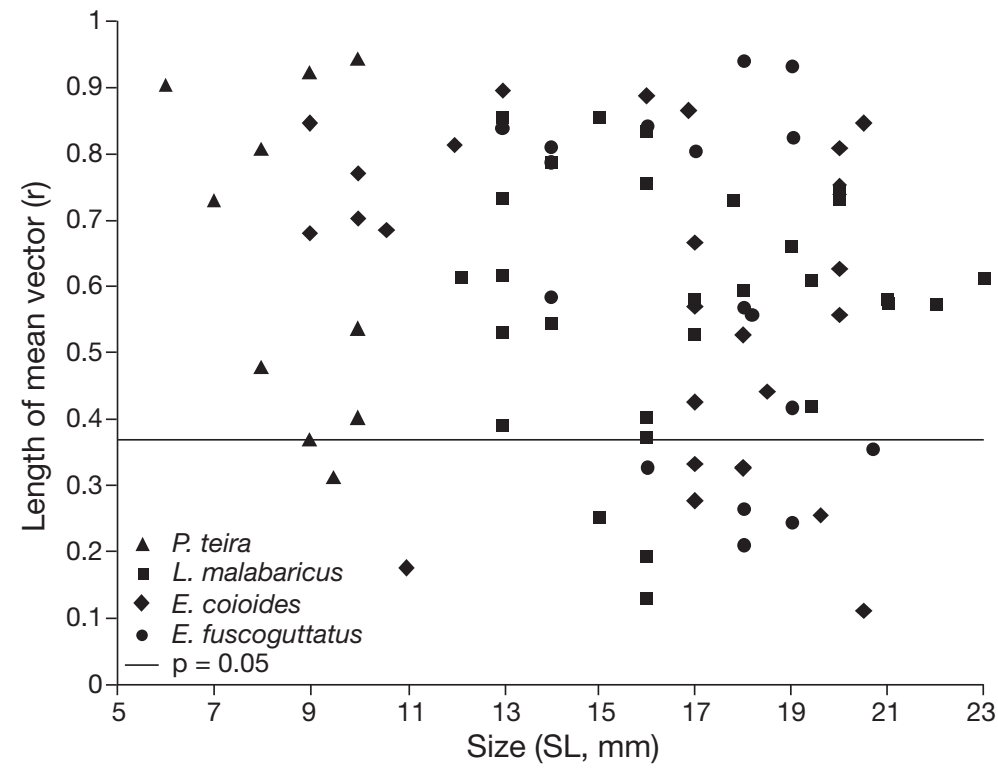

Fig. 6. Precision of swimming orientation (length of mean vector, $r$ ) in larvae of different sizes of 4 species of coral-reef fishes. The horizontal line at $r=0.37$ indicates the $r$-value above which swimming orientation is significantly different from random ( $\mathrm{p}<0.05)$, assuming 21 observations of swimming direction per individual. More than $80 \%$ of individuals were swimming directionally, but there was no obvious ontogenetic trend in either the proportion of directional individuals or in the precision of their orientation

$(\mathrm{RT}, \mathrm{p}=0.34)$. About equal numbers of the larvae swam away from shore as swam toward shore at both study locations. There was not an indication of ontogenetic change in swimming orientation, as none of the 3 size groups of larvae had swimming directionality significantly different from random (RT > 0.17; Fig. 8), and

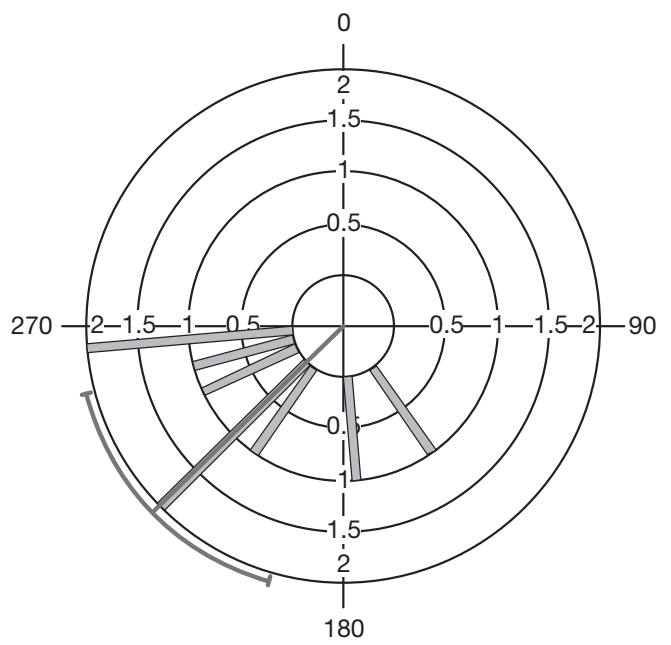

Fig. 7. Platax teira. Frequency distribution of mean swimming directions of directional larvae. The distribution was significantly different from uniform (RT, $\mathrm{p}=0.001)$. Mean direction was $226^{\circ}(r=0.80)$. The radius penetrating the outer circle is the overall mean swimming direction, and the arc bisected by the radius is the $95 \% \mathrm{CI}$ of the mean
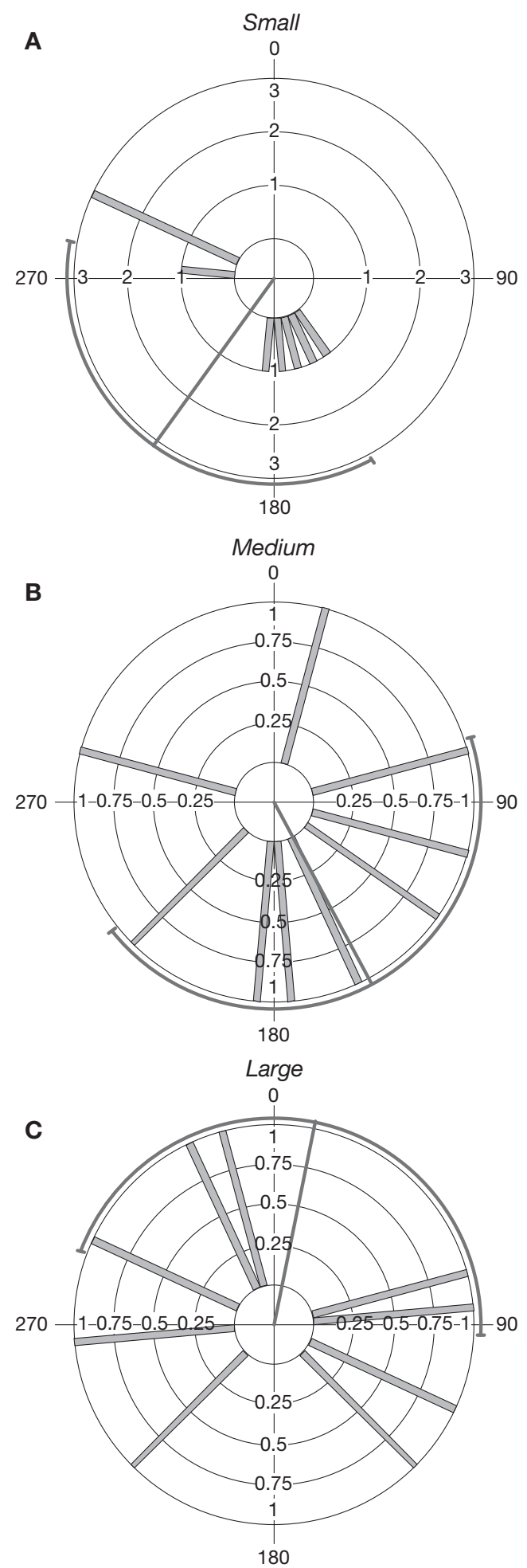

Fig. 8. Lutjanus malabaricus. Frequency distributions of mean swimming directions of directional larvae. Symbols as in Fig. 7. None of the distributions of (A) small (12 to $15 \mathrm{~mm}$ ), (B) medium (16 to $18 \mathrm{~mm}$ ), or (C) large (19 to $21 \mathrm{~mm}$ ) larvae were significantly different from uniform (RT, p > 0.17), and there was no significant difference among the 3 distributions (WW, $\mathrm{p}=0.07$; see Table 6) 
there was no significant difference in swimming direction among the 3 size groups (WW, $\mathrm{p}=0.07$; Table 6). This was in spite of average bearings of the size groups of: small (12 to $15 \mathrm{~mm}), 216^{\circ}$; medium (16 to $18 \mathrm{~mm}$ ), $152^{\circ}$; and large (19 to $21 \mathrm{~mm}$ ), $12^{\circ}$ (Fig. 8A,B). However, the mean value of $216^{\circ}$ for small larvae is somewhat misleading, as the distribution of mean bearings was bimodal, as reflected by a significant result in Rao's test $(\mathrm{p}<0.01)$, with direction modes of westnorthwest and south-southeast (Fig. 8A). This bimodality for small larvae was evident in both study areas, but was not evident for larger larvae. At Her Chen, the modes for small larvae were away from shore (west) and roughly parallel to shore (south), whereas in Nan Wan Bay, the modes were toward shore (west) and away from shore (south) due to differences in the shape and orientation of the coast. Similar modes in both locations imply that they were not the result of location-dependent factors, but rather a fixed pattern of behaviour on the part of smaller larvae.

The 20 directional larvae of Epinephelus coioides had an overall average swimming direction of east-northeast, but this overall distribution of mean swimming directions was not significantly different from random (RT, p = 0.33). Regardless of size or location, only 3 of the 20 larvae swam away from shore: 10 swam toward shore, and 7 swam approximately parallel to shore. There were, however, ontogenetic differences in swimming direction in this species among the 3 size groups of larvae: small $(<12 \mathrm{~mm})$, medium $(13-18 \mathrm{~mm})$ and large $(>18 \mathrm{~mm})$. Small larvae had an average swimming direction of north-northeast ( $\mathrm{RT}, \mathrm{p}=0.01$ ), medium larvae of south-southeast $(\mathrm{RT}, \mathrm{p}=0.06)$ and large larvae of northeast (RT, p $=0.80$ ) (Fig. 9A-C, Table 6). These 3 distributions were significantly different (WW, $p=0.001$; Table 6 ). On a pair-wise basis, the difference between small and medium larvae was significant (WW, $\mathrm{p}<0.001$ ), that between medium and large larvae approached significance (WW, $\mathrm{p}=0.07$ ), and that between small and large larvae was not significant (WW, $\mathrm{p}=0.68$ ). In brief, small larvae, on average, swam toward shore, medium larvae swam away from or perhaps parallel to shore, and large larvae swam, on average, toward shore, but this last distribution did not have significant directionality.

The 12 directional larvae of Epinephelus fuscoguttatus had an overall average swimming direction of north-northeast, but this distribution of the individual mean swimming directions was not significantly different from random $(\mathrm{RT}, \mathrm{p}=0.91)$. About half the larvae swam toward shore and half swam away from shore at the study location in Nan Wan Bay. There were, however, ontogenetic differences in swimming direction between medium and large larvae (no small larvae were studied). On average, medium larvae swam northwest (RT, $\mathrm{p}=0.32$ ), and large larvae swam southeast (RT, $p=0.56$; Fig. 10A,B, Table 6). Although neither of these distributions was significantly different from random, they were significantly different from each other (WW, $\mathrm{p}=0.02$; Table 6 ). The mean direction of medium-sized larvae was toward shore, whereas for large larvae, it was approximately parallel to shore.

\section{Vertical distribution}

Mean depth for each larva was plotted against size to look for possible ontogenetic changes in depth. Although significant linear relationships $(p=0.026$ to 0.030 ) between depth and size were found in 3 species, the relationships were weak, with size explaining only 15 to $36 \%$ of variation in depth. A clearer picture emerged from analysis of the depth-frequency distributions.

Larval Platax teira were very surface orientated. All remained in the upper $7 \mathrm{~m}$ of the water column, and did not swim deeper than our safety depth. There was a significant $(p=0.029)$ ontogenetic ascent of ca. $0.75 \mathrm{~m}$ in mean depth per $1 \mathrm{~mm}$ increase in size, but size explained only $35 \%$ of the variation in mean depth. The depth-frequency distributions of small (6 to $8 \mathrm{~mm}$ ) and large (9 to $11 \mathrm{~mm}$ ) larvae (Fig. 11A) were significantly different (K-S, p < 0.005): small larvae were roughly evenly distributed across the upper $7.5 \mathrm{~m}$, whereas $>70 \%$ of observations of large larvae were in the upper $2.5 \mathrm{~m}$. Depth amplitude ranged from

Table 6. Ontogeny of orientation in larvae of 3 species of coral-reef fishes. For each size grouping, the overall mean swimming direction is based only on directional individuals (n). Also provided are p-values for Rayleigh test and directional precision ( $r$ ). Watson-Williams (WW) tests are for all size groupings of the species. For Platax teira, too few individuals were directional for ontogenetic analysis of orientation. The sizes of larvae in the groupings small, medium and large differ among species, see Table 2

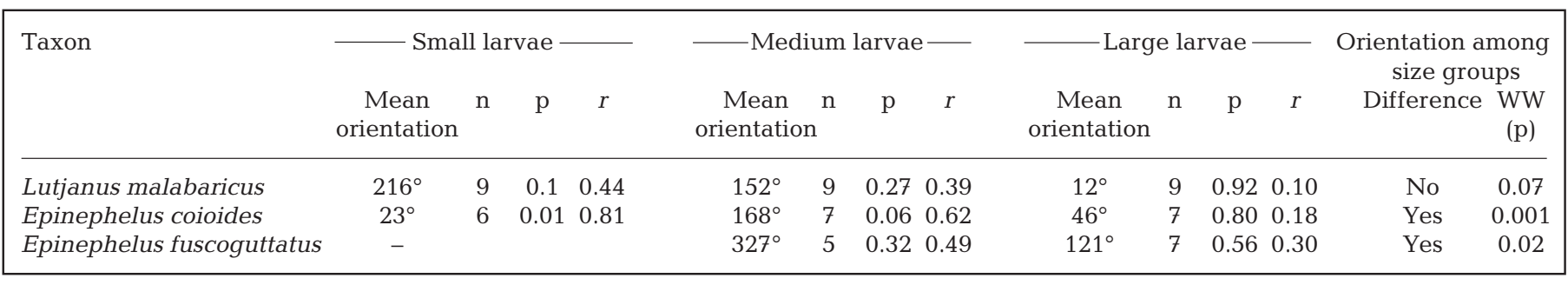



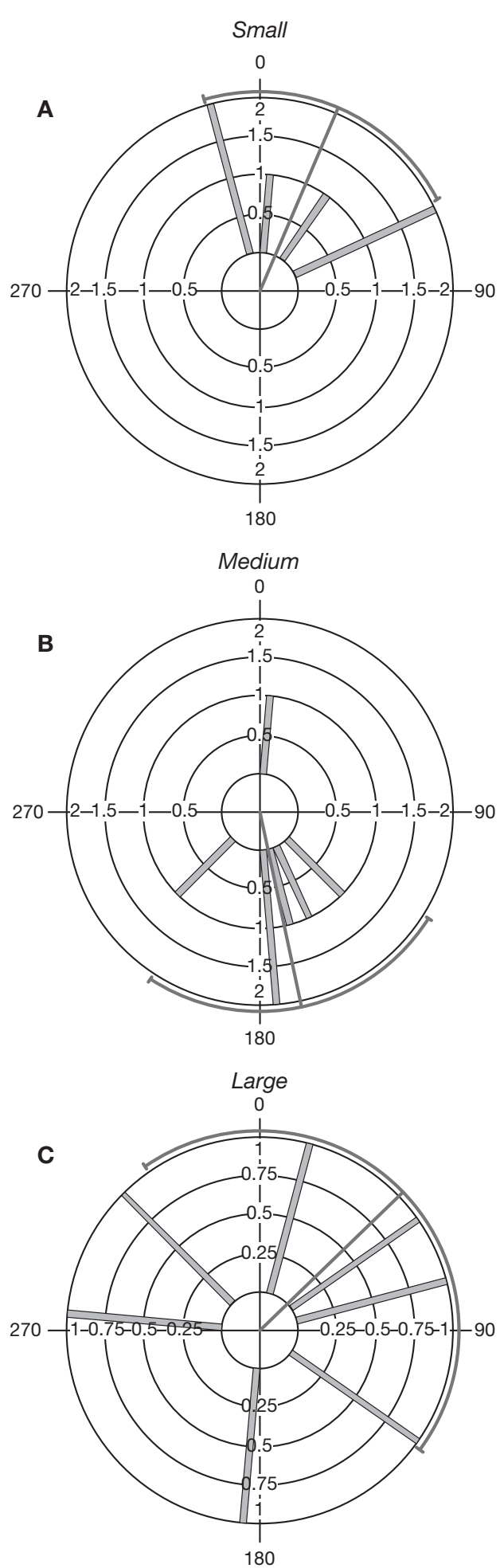

Fig. 9. Epinephelus coioides. Frequency distributions of mean swimming directions of directional larvae. Symbols as in Fig. 7. Compared to a uniform distribution, the distribution of (A) small (9 to $12 \mathrm{~mm}$ ) larvae was significantly different (RT, $\mathrm{p}=0.01)$; (B) medium larvae (13 to $18 \mathrm{~mm}$ ) approached a significant difference ( $\mathrm{RT}, \mathrm{p}=0.06)$; and $(\mathrm{C})$ large larvae (18 to $21 \mathrm{~mm}$ ) was not significantly different (RT, $\mathrm{p}=0.8)$. There was a significant difference among the distributions of the 3 size groupings (WW, $\mathrm{p}<0.001$; see Table 6 )
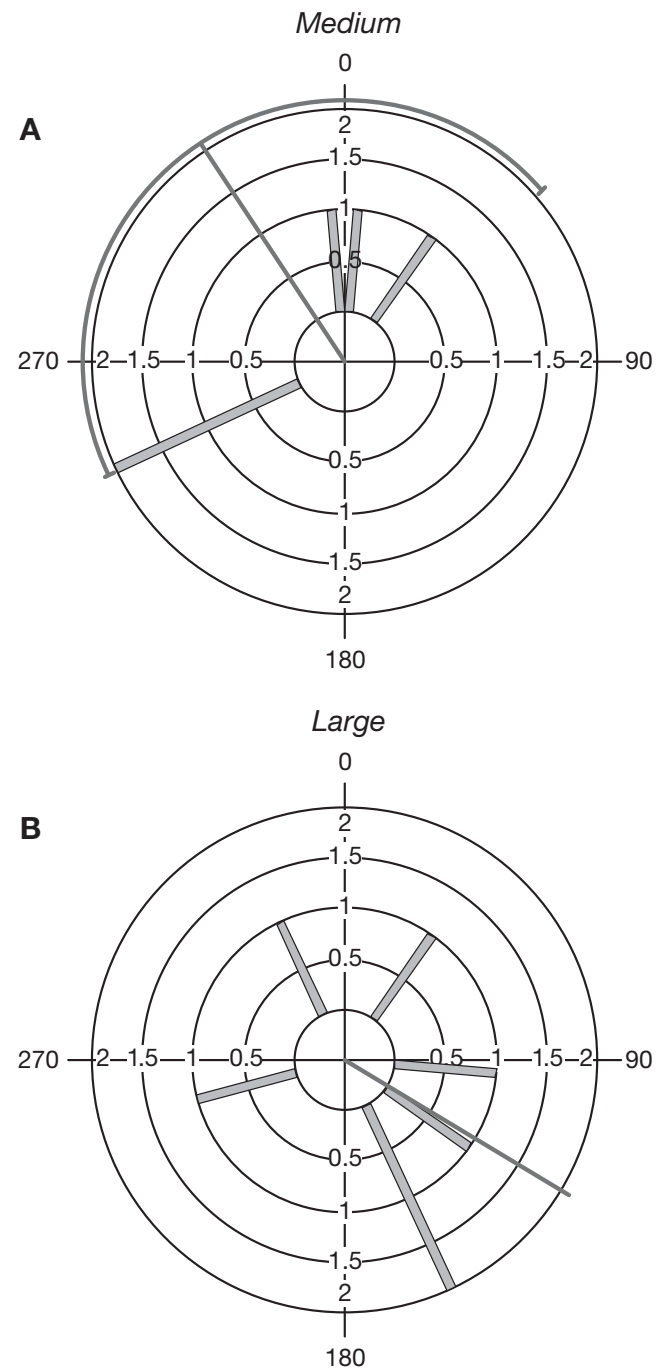

Fig. 10. Epinephelus fuscoguttatus. Frequency distributions of mean swimming directions of directional larvae. Symbols as in Fig. 7. Neither of the distributions of (A) medium (12 to $18 \mathrm{~mm}$ ) nor (B) large larvae (18 to $21 \mathrm{~mm}$ ) were significantly different from uniform (RT, p > 0.3), but the distributions of medium and large larvae were significantly different from each other $(\mathrm{WW}, \mathrm{p}=0.02)$

3 to $6.5 \mathrm{~m}$ (mean $\pm \mathrm{SE}=5.2 \pm 0.4 \mathrm{~m})$, and was not related to size $(\mathrm{p}=0.36)$.

Larval Lutjanus malabaricus had a significant $(\mathrm{p}=$ 0.03 ) ontogenetic descent of about $0.47 \mathrm{~m}$ per $1 \mathrm{~mm}$ increase in size, but size explained only $15 \%$ of variation in mean depth. The ontogenetic descent was more clearly shown in the depth-frequency distributions, where the small larvae were primarily confined to the upper $7.5 \mathrm{~m}$, with a strong mode at 0 to $5 \mathrm{~m}$. The mode of medium-sized larvae was about $2.5 \mathrm{~m}$ deeper than that of small larvae, and large larvae had a broader and deeper mode (Fig. 11B). About one-third of the observations of large larvae were at depths $>10 \mathrm{~m}$, whereas fewer than $10 \%$ of the observations of small and 
medium larvae were that deep. The depth-frequency distributions of the 3 size classes of larvae were significantly different (K-S, p < 0.0001). The only L. malabaricus larvae $(\mathrm{n}=3)$ that swam deeper than our safety depth were large $(>19 \mathrm{~mm})$, which is consistent with an ontogenetic descent. Depth amplitude ranged from 2.1 to $16.9 \mathrm{~m}$ (mean $\pm \mathrm{SE}=6.5 \pm 0.7 \mathrm{~m}$ ), and was not related to size $(p=0.20)$.

Larvae of Epinephelus coioides had a significant ( $\mathrm{p}=$ 0.026 ) ontogenetic ascent of about $0.37 \mathrm{~m}$ in mean depth per $1 \mathrm{~mm}$ of size increase, but the size of larvae explained only $16 \%$ of the variation in mean depth. In contrast, there was no significant difference in depthfrequency among the 3 size classes of larvae (K-S, p > 0.05 ): all 3 size classes had a mode between 2.5 and $7.5 \mathrm{~m}$ (Fig. 11C). However, some apparent difference was evident in that only the smallest larvae spent

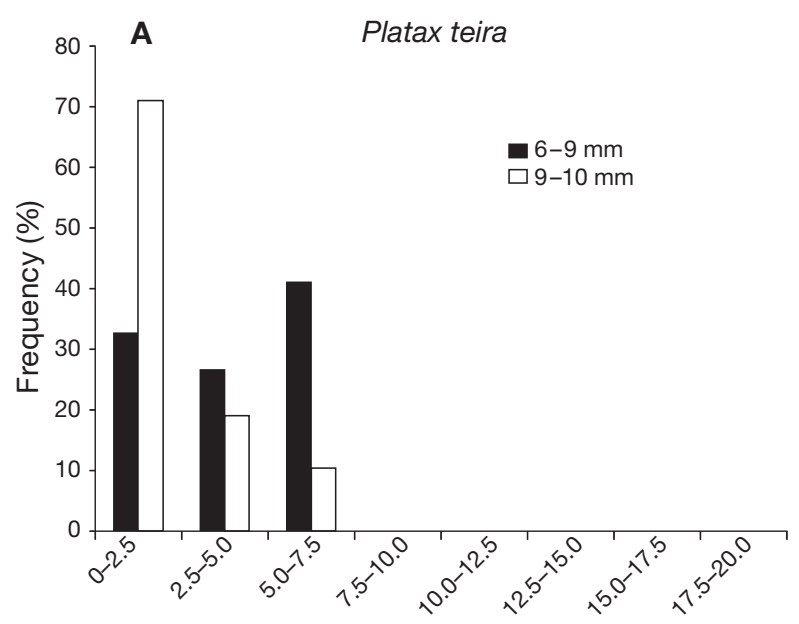

B

Lutjanus malabaricus

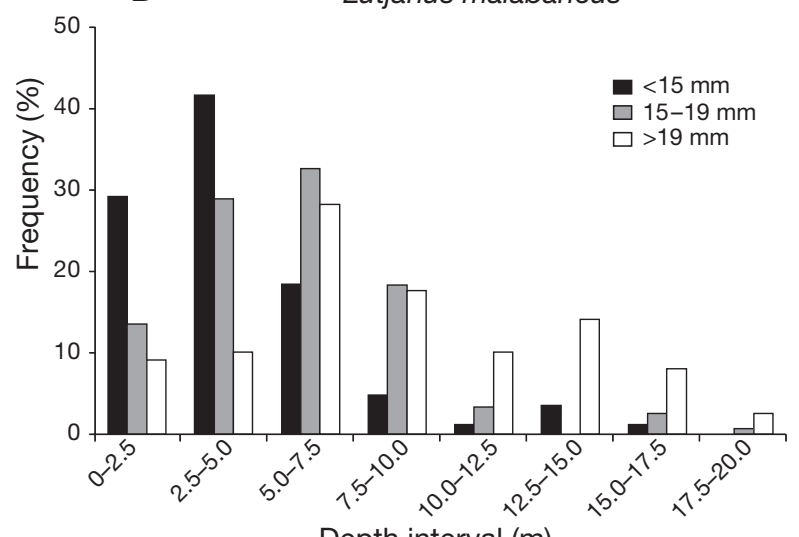

Depth interval $(\mathrm{m})$
$>10 \%$ of their time deeper than $10 \mathrm{~m}$. In addition, the 6 E. coioides larvae that swam deeper than our safety depth were all $\leq 15 \mathrm{~mm}$, which is consistent with an ontogenetic ascent. Depth amplitude ranged from 2.1 to $14.5 \mathrm{~m}$ (mean $\pm \mathrm{SE}=8.7 \pm 0.7 \mathrm{~m}$ ), and amplitude decreased with increasing size of larvae at about $0.5 \mathrm{~m}$ $\mathrm{mm}^{-1}$ (ampl. $=-0.51 \mathrm{SL}+16.72, \mathrm{R}^{2}=0.25, \mathrm{p}=0.002$ ), although the relationship explained only $25 \%$ of the variation in amplitude. Hence, it seems that the apparent ontogenetic ascent is driven in part by ontogenetic changes in amplitude.

Epinephelus fuscoguttatus larvae had no apparent ontogenetic change in vertical distribution. There was no significant relationship between size and mean depth $(p=0.67)$, nor was there any difference in depthfrequency distribution between medium-sized and large larvae (K-S, p > 0.2; Fig. 11D). Similar numbers of

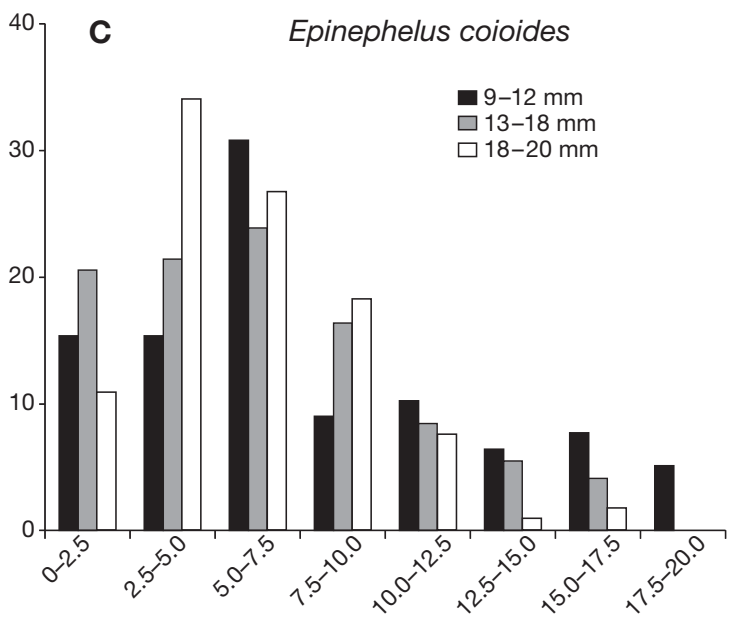

D

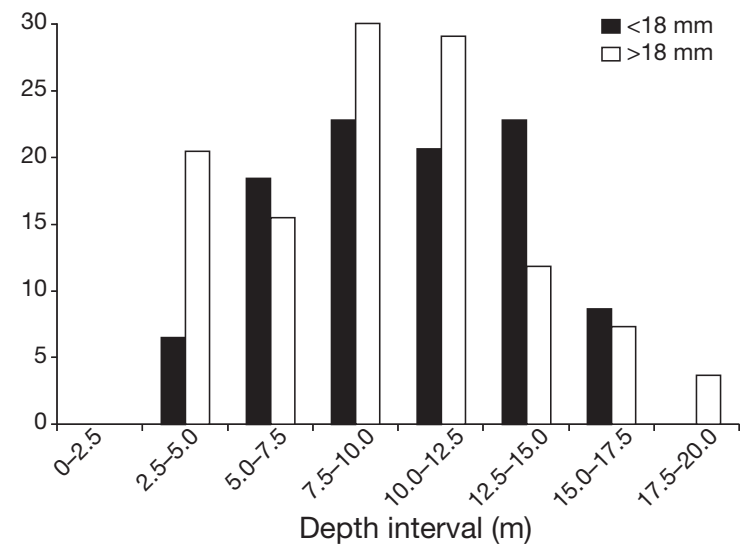

Fig. 11. Depth-frequency distributions of different size groupings of larvae of 4 species of coral-reef fishes. The numbers of larvae and of depth observations used in the test for each size grouping are given in Table 2. (A) Platax teira. The depth-frequency distributions of the 2 size groups of larvae were significantly different: K-S, p < 0.005. (B) Lutjanus malabaricus. The depthfrequency distributions of the 3 size groupings of larvae were significantly different: K-S, p $<0.0001$. (C) Epinephelus coioides. The depth-frequency distributions of the 3 size groupings of larvae were not significantly different: K-S, p >0.05. (D) Epinephelus fuscoguttatus. The depth-frequency distributions of the 2 size groupings of larvae were not significantly different: K-S, $\mathrm{p}<0.20$. In contrast, the depth-frequency distributions of both medium and small larvae of E. fuscoguttatus were significantly deeper than those of E. coioides (K-S, p > 0.0001) 
medium-sized $(\mathrm{n}=5)$ and large $(\mathrm{n}=4)$ larvae swam deeper than our safety depth. The larvae occurred primarily between 5 and $15 \mathrm{~m}$ in the middle of the water column. Depth amplitude ranged from 5.5 to $15.4 \mathrm{~m}$ (mean $\pm \mathrm{SE}=9.2 \pm 0.6 \mathrm{~m})$, and was not related to the size of larvae ( $\mathrm{p}>0.20)$.

The 2 Epinephelus species had significantly different depth-frequency distributions (K-S, p < 0.0001). In both medium-sized and large larvae, modes of $E$. fuscoguttatus were about $10 \mathrm{~m}$ deeper than modes of E. coioides (Fig. 11C,D).

\section{DISCUSSION}

Understanding of development of behavioural capabilities in marine fish larvae is limited. The present study is one of a few based on observations of larvae in the ocean over a range of developmental stages and sizes (Leis 2006, Leis et al. 2006a,b, 2009) and the first based on larvae of demersal, coral-reef fishes. Knowledge of larval behaviour in reef fishes is based largely on a few families, particularly pomacentrids and apogonids, which lack pelagic eggs, large adult size and commercial value. In contrast, the species studied here spawn pelagic eggs, attain reasonably large size and are commercially important. Further, their larvae represent a range of morphologies and life-history patterns. Except for limited information on in situ speed (see Leis \& Carson-Ewart 1997), nothing is known of in situ larval behaviour in the genera Platax, Lutjanus and Epinephelus.

As found in other studies (Fisher \& Leis 2009), speed at any size varied considerably, and, as a consequence, the $\mathrm{R}^{2}$ values even of the significant speed versus size relationships were low $(<0.55)$. This is an indication that factors in addition to size are important in determining swimming speed in the sea. This includes, for example, condition and motivation of larvae (internal factors), but also variable environmental conditions found in the sea (external factors), including sensory cues (Finn \& Kapoor 2008). Individuals may react to sensory cues differently depending on their stage of development, or time of day (Kingsford et al. 2002). Although size is generally a better predictor of development than is age (Fuiman \& Higgs 1997), it is clear that size at settlement does vary, indicating that attainment of settlement competence, at least, is not perfectly predicted by size.

Small, slow animals operate in a viscous hydrodynamic environment where swimming is energetically inefficient, and it is often assumed that this applies to larvae of fishes (Webb \& Weihs 1986). Only the smallest, slowest larvae we studied were not swimming in a largely inertial hydrodynamic environment (as indi- cated by $\operatorname{Re}>1000)$. All studied larvae were doing so by 8 to $14 \mathrm{~mm}$, depending on species, and were therefore able to effectively escape efficiency-sapping viscous forces. Thus, the assumption that larval reef fishes swim inefficiently in a viscous hydrodynamic environment appears unjustified for a major portion of their pelagic stage. This indication of efficient, inertial swimming in the ocean helps explain the high swimming endurance found in reef-fish larvae for a large portion of their pelagic stage (Stobutzki \& Bellwood 1997, Fisher \& Bellwood 2001, Leis \& Clark 2005, Leis et al. 2006a, 2009). Endurance has not been reported in our study species, but it is uniformly high in settlement-stage larvae of coral-reef fishes (Stobutzki \& Bellwood 1997). Further, endurance at speeds similar to the in situ speeds reported here increases rapidly from sizes of about 8 to $10 \mathrm{~mm}$ to reach $10 \mathrm{~s}$ of kilometres at settlement (Fisher et al. 2000, Clark et al. 2005, Leis et al. 2006a, 2009). Therefore, we expect that estimates of in situ speed over $10 \mathrm{~min}$ are representative of sustained swimming speeds in the sea (Fisher \& Leis 2009).

All 4 of the study species had significant linear relationships between size and swimming speed $\left(U_{\text {crit }}\right)$ in the laboratory (Leis et al. 2007a), and these relationships had much higher $\mathrm{R}^{2}$ values $(0.22$ to 0.73 higher, depending on species) than those found between size and speed in the sea. This implies that factors in addition to condition and capacity play a role in determining swimming speed in the field, because the larvae came from the same sources in both laboratory and field studies, so condition of larvae should have been similar in both. In Lutjanus malabaricus over the 12 to $23 \mathrm{~mm}$ size range, in situ speed did not increase significantly (mean speed was $17 \mathrm{~cm} \mathrm{~s}^{-1}$ ), whereas in the laboratory, critical speed increased from ca. 16 to $41 \mathrm{~cm} \mathrm{~s}^{-1}$. In particular, in the sea, larger larvae chose to swim much more slowly than they were able, whereas smaller larvae were swimming close to their potential $\left(U_{\text {crit }}\right)$ performance. In some cases, 'behavioural compensation occurs when functionally limited animals (e.g. an animal that is constrained to run slowly because of its small size) exert more effort' (Dial et al. 2008), a situation consistent with swimming of L. malabaricus larvae. In addition, behavioural compensation was apparent in Platax teira larvae, which, at 6 to $11 \mathrm{~mm}$, were the smallest larvae we studied. Larvae of $P$. teira had in situ speeds that averaged $87 \%$ of their swimming capability as measured by critical speed. In contrast, the larvae of the other 3 study species (which were larger than $P$. teira), swam in the sea at 39 to $67 \%$ of their critical speed. This serves as a reminder that laboratory measures of behaviour need to be 'ground truthed' in the field. 
When estimating the influence of behaviour on dispersal, consideration of the abilities of the best - rather than average-performers may be relevant. In this study, the fastest individuals within each size interval were several to $10 \mathrm{~cm} \mathrm{~s}^{-1}$ faster than mean performance, and this superior performance would be expected to result in more behavioural influence on dispersal outcomes and greater volumes searched for food, but also in greater demand for food. Recent evidence from several systems and a variety of species indicates that the fastest growing individual larvae may be the ones that survive to settlement (e.g. Vigliola \& Meekan 2002, Jenkins \& King 2006). Therefore, it may be the best performers in other areas, such as swimming speed, that preferentially survive to reach a settlement site, and, if so, the exceptional performers should be the focus of considerations of dispersal and connectivity.

Critical speed can be used to predict swimming speed in the sea, but the relationships between critical speed and in situ speed are species specific. Among the 4 study species, Platax teira and Epinephelus coioides had strong relationships $\left(\mathrm{R}^{2}>0.7\right)$ between the 2 measures of speed that could be used for predicting swimming speed in the sea. In contrast, Lutjanus malabaricus and E. fuscoguttatus, had low $\mathrm{R}^{2}$ values $(0.2$ to 0.4 ), and, for these, the overall mean ratio of in situ speed to critical speed of 0.4 to 0.6 provides a better means of estimating in situ speed from critical speed.

Size and morphology of settlement-stage fish larvae can predict swimming ability (Fisher \& Hogan 2007). In a study comparing a wide range of taxa, Fisher \& Hogan (2007) found size to be the most important predictor of swimming speed, but did not consider the effects of long fin spines on swimming speed. They also found, perhaps surprisingly, that body width was not a strong predictor of swimming speed $\left(U_{\text {crit }}\right)$. Beyond that, they showed that aspects of the shape and size of the caudal fin and caudal peduncle were the most important morphological predictors of swimming ability. However, Fisher \& Hogan (2007) worked with settlement-stage larvae at a limited, late stage in development, which makes their results difficult to apply to the present study. The morphology of our study species fell into 3 groups: (1) initially rotund, but later very deep-bodied and compressed (Platax teira); (2) deep-bodied, but strongly compressed, with very long, robust fin spines (Lutjanus malabaricus); and (3) moderately deep bodied and moderately compressed, with some fin spines even longer than in Group 2 (Epinephelus species). None of these species could be considered 'streamlined', and the long fin spines of the lutjanid and serranids would probably be an impediment to swimming. In $P$. teira it is likely that the radical changes in body shape found in this family (see Leis \&
Carson-Ewart 2004) contributed to the high variance in speed found in the larger individuals of this species. The fin spines of the other 3 species became relatively much smaller with growth, and this also was likely to have influenced swimming speed. So, attempts to relate swimming ability to morphology in the study species would be problematical. It is notable that scaled swimming speeds in the study species remained largely between 5 and $15 \mathrm{BL} \mathrm{s}^{-1}$ throughout development, in spite of large differences in morphology among species and large changes in morphology within species. One might expect that more streamlined species that lack very long, robust fin spines would be faster swimmers than the species studied here, and there is some support for such an expectation from comparisons of swimming speeds of settlementstage larvae. Morphologically unspecialized pomacentrids, for example, have some of the highest scaled in situ speeds of any reef fishes at settlement, with many species possessing mean speeds of 20 to $34 \mathrm{BL} \mathrm{s}^{-1}$ (Leis \& Carson-Ewart 1997, Leis et al. 2007b).

Reared larvae, such as those used in the present study, may behave differently from wild larvae, and most concern centres on possible inferior performance of reared larvae (Blaxter 1976). Direct comparisons between reared and wild larvae are few, and have provided mixed results; our comparisons are similarly mixed. There are no previous in situ behavioural studies on larvae of the study species, but there is information on swimming speed of congeners and confamilials (Leis \& Carson-Ewart 1997, Leis \& Fisher 2006). A $9 \mathrm{~mm}$, wild Platax pinnatus swam at $4.9 \mathrm{~cm} \mathrm{~s}^{-1}$, whereas 8 to $10 \mathrm{~mm}$ reared $P$. teira larvae swam at 3.7 to $20.1 \mathrm{~cm} \mathrm{~s}^{-1}$ (mean $\pm \mathrm{SE}=12.9 \pm 1.8$ ), bracketing the wild speed. For Lutjanus spp., 21 to $26 \mathrm{~mm}$ wild larvae of Lutjanus carponotatus and L. fulviflamma $(\mathrm{n}=1)$ swam at $24.2( \pm 2.3)$ and $14.5 \mathrm{~cm} \mathrm{~s}^{-1}$, respectively, whereas 21 to $26 \mathrm{~mm}$ reared larvae of $L$. malabaricus swam at $17.3( \pm 2.2) \mathrm{cm} \mathrm{s}^{-1}$. There are no data on in situ speeds of Epinephelus spp. larvae, but in situ speeds are available for the morphologically similar serranid Plectropomus leopardus. Wild P. leopardus larvae of ca. $17 \mathrm{~mm}$ swam at $13( \pm 2.2) \mathrm{cm} \mathrm{s}^{-1}$, whereas 16 to $18 \mathrm{~mm}$ reared larvae of E. coioides and E. fuscoguttatus had speeds of $22.4( \pm 1.5)$ and $16.1( \pm 2.2) \mathrm{cm} \mathrm{s}^{-1}$, respectively. Most of the wild larvae had speeds that bracketed those of confamilials, or were similar to them. Thus, the reared larvae had speeds that were not clearly different from those of the wild larvae, and a similar result was obtained for critical speed (Leis et al. 2007a).

Orientation of fish larvae in situ is little studied, but the results obtained here parallel those from other work. Variation in orientation among species has also been found in studies of orientation (Leis et al. 1996, 
2006a,b, 2007b, Leis \& Carson-Ewart 2001, 2003, Hindell et al. 2003). Pelagic orientation in larval ephippids and lutjanids has not been reported before, and work on serranid orientation is limited to a study that focused on settlement behaviour (Leis \& Carson-Ewart 1999). But, the available studies describe orientation behaviour that is roughly similar within families and that differs among families. The very limited work on the ontogeny of orientation in larval fishes is consistent with the present results in showing that orientation ability develops relatively early in the larval stage, but then its precision does not improve with ontogeny, and that ontogenetic changes in the direction of orientation are common. A final similarity among all studies is the relatively low precision of orientation by fish larvae.

Regardless of whether orientation was characterized in relation to habitat, in this case, toward shore or away from shore, or in relation to compass direction, larvae in the present study had a variety of orientation behaviours. One species swam offshore (southwest). One species had bimodal directionality that was along the same compass directions in both locations, but that translated to offshore and roughly parallel to shore at one location, but offshore and onshore at the other. Two species had ontogenetic changes in orientation: in one species, small and large larvae swam toward shore, while medium larvae swam offshore, and, in the other, medium larvae swam toward shore and large larvae swam parallel to shore. Given this variety, it is difficult to suggest that orientation in these species is in response to the same cue or cues. In fact, different cues may be used by different species or stages (Kingsford et al. 2002). The bimodality in orientation found in 1 species suggests a cue, such as sound, in which a $180^{\circ}$ ambiguity has been predicted (Montgomery et al. 2006), or it may represent an attempt by larvae to remain in a specific area by alternating their swimming directions. The alternating ontogenetic patterns of orientation found in 2 species may also represent an attempt to remain in a specific area. Although the larger larvae we observed in situ were of settlement size and frequently swam over reefs, none made any attempt to settle or even to closely examine the reefs.

The behaviours observed were within the range of those found in previous field studies of larval-fish behaviour, although there have been few such studies that examined a range of sizes and states of development. Over a size range of 6 to $24 \mathrm{~mm}$, larvae swam at 4 to $30 \mathrm{~cm} \mathrm{~s}^{-1}$, equivalent to 4 to $20 \mathrm{BL} \mathrm{s}^{-1}$. This is similar to in situ speeds reported for larvae of other species of similar size (Leis 2006). Orientation precision did not change with size, nor did the percentage of individuals that swam directionallyresults that are in line with previous studies (Leis et al. 2006a,b, 2009). The 4 species differed in their orientation: 1 species was highly orientated, 2 species had ontogenetic changes in orientation, and 1 species had neither significant orientation, nor ontogenetic changes in orientation.

The combination of swimming speeds in the same range as coastal current speeds and orientation ability means that the larvae of the species studied have the ability to directly influence dispersal outcomes through horizontal swimming (Power 1984). Even the smallest larvae we studied $(6 \mathrm{~mm})$ were capable of swimming at $>3 \mathrm{~cm} \mathrm{~s}^{-1}$, which means they should be able to influence dispersal outcomes (Leis 2006). The average swimming speeds of larger larvae were faster than those of average currents in many coastal areas and are therefore 'effective' (sensu Leis \& Stobutzki 1999). In addition, the best performers were 3 to $6 \mathrm{~cm} \mathrm{~s}^{-1}$ faster than mean performers, allowing greater influence. But, larvae need not swim faster than ambient currents to influence dispersal outcomes, as much will depend on the orientation of their swimming. Orientation ability was also present in the smallest larvae studied, which indicates that the ability to directly influence dispersal outcomes is present in larvae from early in the pelagic stage.

It seems unlikely that the buoyancy of the larvae (which was accommodated to the surface when released) would have strongly influenced their vertical distribution behaviour (Govoni \& Forward 2008). Previous work using in situ methodology (e.g. Leis \& Carson-Ewart 2001, Leis 2004) shows that individual larvae often swim over a range of depths during short time intervals and that larvae select different depths in different locations, a clear indication that buoyancy per se is not an overriding influence in depth selection. In 2 families, a loose correlation $\left(\mathrm{R}^{2}=0.45\right.$ to 0.47$)$ was found between pressure preference of larvae tested in the laboratory and their capture depth, but no correlation was found in 2 other families (Huebert 2008). This again suggests that buoyancy is not a strong determinant of vertical distribution, especially in larvae that swim strongly.

By controlling their vertical distribution, larvae can potentially influence their dispersal indirectly where current velocity differs with depth, as it does in many coastal environments. Vertical distribution behaviour differed not only among species, as might be expected (Leis 2004), but also ontogenetically. One species was particularly surface oriented, another avoided the surface and was most common at 7 to $12 \mathrm{~m}$, whereas the other 2 species had wide vertical distributions, with modes between 2.5 and $7.5 \mathrm{~m}$. Two species undertook ontogenetic ascents, 1 species undertook an ontogenetic descent, and 1 species showed no ontogenetic difference in vertical distribu- 
tion. Therefore, the manner in which vertical distribution might influence dispersal will vary among species and will also vary at different stages in development within a species.

Surprisingly strong behavioural differences were found between the 2 species of Epinephelus. These serranid species differed in swimming speed, at least initially, in orientation, and in vertical distribution, in spite of the fact that they are very similar morphologically. Perhaps this difference is connected with their different habitat requirements as adults. Adult E. coioides live on inshore coral reefs, often in turbid waters, including estuaries, whereas adult E. fuscoguttatus live on coral reefs in more offshore, clear water. Possibly, different behaviours by the larvae are required in the 2 different habitats.

The present study documents differences in behaviour among both species and developmental stages of larval reef fishes: differences that have important implications for dispersal and, therefore, for connectivity. Behavioural differences among the larvae of the study species would result in different dispersal trajectories even for larvae within the same water mass at the same time. Further, because the behaviours studied here differ with size (and age) of the larvae, the extent to which behaviours can influence dispersal trajectories and the way in which they influence them will differ with size (and age). The developmental trajectories of the behaviours also differ among species, meaning that it will be difficult to predict how and to what extent behaviour may influence dispersal in other reef-fish species. This indicates it is misleading to adopt a one-size-fits-all approach to incorporating larval-fish behaviour into considerations of larval dispersal either among species, or even within species at different stages in developmental (Leis 2007).

Acknowledgements. We thank many who contributed to the success of this work: K.-T. Shao, C. Wen and K.-P. Kan of Academica Sinica, who made our work in Taiwan possible, and the Director, L.-S. Fang, and staff of NMMBA, particularly J.-P. Chen, I.-S. Chen and C.-Y. Chung, for their excellent cooperation. We thank L.-H. Chao, who spent many hours helping us obtain larvae, and the Taiwanese aquaculturists who provided larvae. The skipper of our dive boat, R.-M. Chen, enabled us to dive efficiently and safely. M. Brown, D. Clark, R. Piola and K. J. Wright assisted us ably in the laboratory and field. R. N. Johnson confirmed the identification of our Lutjanus malabaricus larvae with genetic methods. M. Lockett assisted with data analysis and figures, and S. Bullock and M. Yerman provided editorial assistance. This research was supported by an ARC Discovery grant (DP0345876), a DST International Science Linkages grant (IAP-IST-CG030043), and a MTSRF grant to J.M.L. and by the Australian Museum. This research was carried out under Research Approval 01-01 from the Australian Museum Animal Care and Ethics Committee.

\section{LITERATURE CITED}

Almany GR, Berumen ML, Thorrold SR, Planes S, Jones GP (2007) Local replenishment of coral reef fish populations in a marine reserve. Science 316:742-744

Batschelet E (1981) Circular statistics in biology. Academic Press, London

Blaxter JHS (1976) Reared and wild fish-How do they compare? In: Persoone G, Jaspers E (eds) Proceedings of the 10th European Symposium on Marine Biology, Vol 1. Universa Press, Wettern, p 11-26

Blaxter JHS (1986) Development of sense organs and behavior of teleost larvae with special reference to feeding and predator avoidance. Trans Am Fish Soc 115:98-114

Clark DL, Leis JM, Hay AC, Trnski T (2005) Swimming ontogeny of larvae of four temperate marine fishes. Mar Ecol Prog Ser 292:287-300

Cowen RK (2002) Larval dispersal and retention and consequences for population connectivity. In: Sale PF (ed) Coral reef fishes: dynamics and diversity in a complex ecosystem. Academic Press, San Diego, CA, p 149-170

Cowen RK, Gawarkiewicz G, Pineda J, Thorrold SR, Werner FE (2007) Population connectivity in marine systems: an overview. Oceanography 20:14-21

> Dial KP, Greene E, Irschick DJ (2008) Allometry of behavior. Trends Ecol Evol 23:394-401

Finn RN, Kapoor BG (eds) (2008) Fish larval physiology. Science Publishers, Enfield, NH

> Fisher R, Bellwood DR (2001) Effects of feeding on the sustained swimming abilities of late-stage larval Amphiprion melanopus. Coral Reefs 20:151-154

> Fisher R, Hogan D (2007) Morphological predictors of swimming speed: a case study of pre-settlement juvenile coral reef fishes. J Exp Biol 210:2436-2443

Fisher R, Leis JM (2009) Swimming performance in larval fishes: from escaping predators to the potential for long distance migration. In: Domenici P, Kapoor BG (eds) Fish locomotion: an etho-ecological perspective. Science Publishers, Enfield, NH, p 333-373

Fisher R, Bellwood DR, Job SD (2000) Development of swimming abilities in reef fish larvae. Mar Ecol Prog Ser 202:163-173

Fuiman LA, Higgs DM (1997) Ontogeny, growth and the recruitment process. In: Chamber RC, Trippel EA (eds) Early life history and recruitment in fish populations. Chapman and Hall, London, p 225-249

Fuiman LA, Werner RG (eds) (2002) Fishery science: the unique contributions of early life stages. Blackwell, Oxford

Fulton CJ (2007) Swimming speed performance in coral reef fishes: field validations reveal distinct functional groups. Coral Reefs 26:217-228

Gaines SD, Gaylord B, Gerber LR, Hastings A, Kinlan BP (2007) Connecting places: the ecological consequences of dispersal in the sea. Oceanography 20:90-99

Govoni JJ, Forward RB (2008) Buoyancy. In: Finn RN, Kapoor BG (eds) Fish larval physiology. Science Publishers, Enfield, NH, p 495-521

Hindell JS, Jenkins GP, Moran SM, Keough MJ (2003) Swimming ability and behaviour of post-larvae of a temperate marine fish re-entrained in the pelagic environment. Oecologia 135:158-166

Huebert KB (2008) Barokinesis and depth regulation by pelagic coral reef fish larvae. Mar Ecol Prog Ser 367: 261-269

Jenkins GP, King D (2006) Variation in larval growth can predict the recruitment of a temperate, seagrass-associated fish. Oecologia 147:641-649 
Kingsford MJ, Leis JM, Shanks A, Lindeman K, Morgan S, Pineda J (2002) Sensory environments, larval abilities and local self-recruitment. Bull Mar Sci 70:309-340

Legendre P (2001) Model II regression—User's guide. Département de sciences biologiques. Université de Montréal, Montreal. Available at: www.bio.umontreal.ca/casgrain/en/ labo/model-ii.html

Leis JM (2004) Vertical distribution behaviour and its spatial variation in late-stage larvae of coral-reef fishes during the day. Mar Freshwat Behav Physiol 37:65-88

Leis JM (2006) Are larvae of demersal fishes plankton or nekton? Adv Mar Biol 51:57-141

Leis JM (2007) Behaviour as input for modelling dispersal of fish larvae: behaviour, biogeography, hydrodynamics, ontogeny, physiology and phylogeny meet hydrography. Mar Ecol Prog Ser 347:185-193

Leis JM, Carson-Ewart BM (1997) In situ swimming speeds of the late larvae of some coral reef fishes. Mar Ecol Prog Ser 159:165-174

Leis JM, Carson-Ewart BM (1998) Complex behaviour by coral-reef fish larvae in open-water and near-reef pelagic environments. Environ Biol Fishes 53:259-266

Leis JM, Carson-Ewart BM (1999) In situ swimming and settlement behaviour of larvae of an Indo-Pacific coral-reef fish, the coral trout (Pisces, Serranidae, Plectropomus leopardus). Mar Biol 134:51-64

Leis JM, Carson-Ewart BM (2001) Behavioural differences in pelagic larvae of four species of coral-reef fishes between two environments: ocean and atoll lagoon. Coral Reefs 19: $247-257$

Leis JM, Carson-Ewart BM (2003) Orientation of pelagic larvae of coral-reef fishes in the ocean. Mar Ecol Prog Ser 252:239-253

Leis JM, Carson-Ewart BM (eds) (2004) The larvae of IndoPacific coastal fishes: a guide to identification (Fauna Malesiana Handbook 2, 2nd edn). Brill, Leiden

Leis JM, Clark DL (2005) Feeding greatly enhances endurance swimming of settlement-stage reef-fish larvae (Pomacentridae). Ichthyol Res 52:185-188

Leis JM, Fisher R (2006) Swimming speed of settlement-stage reef-fish larvae measured in the laboratory and in the field: a comparison of critical speed and in situ speed. In: Proceedings of the 10th International Coral Reef Symposium. Coral Reef Society of Japan, Tokyo, p 438-445

Leis JM, Stobutzki IC (1999) Swimming performance of late pelagic larvae of coral-reef fishes: in situ and laboratorybased measurements. In: Séret B, Sire JY (eds) Proceedings of the 5th Indo-Pacific Fish Conference. Société Française d'Ichtyologie \& Institut de Recherche pour le Développment, Paris, p 575-583

Leis JM, Sweatman HPA, Reader SE (1996) What the pelagic stages of coral reef fishes are doing out in blue water: daytime field observations of larval behaviour. Mar Freshw Res 47:401-411

Editorial responsibility: Charles Birkeland, Honolulu, Hawaii, USA
Leis JM, Hay AC, Clark DA, Chen IS, Shao KT (2006a) Behavioral ontogeny in larvae and early juveniles of the giant trevally, Caranx ignobilis (Pisces: Carangidae). Fish Bull 104:401-414

Leis JM, Hay AC, Trnski T (2006b) In situ behavioural ontogeny in larvae of three temperate, marine fishes. Mar Biol 148:655-669

Leis JM, Hay AC, Lockett MM, Chen JP, Fang LS (2007a) Ontogeny of swimming speed in larvae of pelagicspawning, tropical, marine fishes. Mar Ecol Prog Ser 349: 255-269

Leis JM, Wright KJ, Johnson RN (2007b) Behaviour that influences dispersal and connectivity in the small, young larvae of a reef fish. Mar Biol 153:103-117

Leis JM, Piola RF, Hay AC, Wen C, Kan KP (2009) Ontogeny of behaviour relevant to dispersal and connectivity in larvae of two non-reef demersal, tropical fish species. Mar Freshw Res 60: in press

Miller TJ, Crowder LB, Rice JA, Marschall EA (1988) Larval size and recruitment mechanisms in fishes: toward a conceptual framework. Can J Fish Aquat Sci 45:1657-1670

> Montgomery JC, Jeffs A, Simpson SD, Meekan M, Tindle C (2006) Sound as an orientation cue for the pelagic larvae of reef fishes and decapod crustaceans. Adv Mar Biol 51: $143-196$

Power JH (1984) Advection, diffusion, and drift migrations of larval fish. In: McCleave JD, Arnold GP, Dodson JJ, Neil WH (eds) Mechanisms of migration in fishes. Plenum Press, New York, p 27-37

- Roberts CM (1997) Connectivity and management of Caribbean coral reefs. Science 278:1454-1456

Sale PF (ed) (1991) The ecology of fishes on coral reefs. Academic Press, San Diego, CA

Stobutzki IC, Bellwood DR (1997) Sustained swimming abilities of the late pelagic stages of coral reef fishes. Mar Ecol Prog Ser 149:35-41

Swearer SE, Shima JS, Hellberg ME, Thorrold SR and others (2002) Evidence of self-recruitment in demersal marine populations. Bull Mar Sci 70:251-272

Vigliola L, Meekan MG (2002) Size at hatching and planktonic growth determine post-settlement survivorship of a coral reef fish. Oecologia 131:89-93

> Webb PW, Weihs D (1986) Functional locomotor morphology of early life history stages of fishes. Trans Am Fish Soc 115: $115-127$

Werner FE, Cowen RK, Paris CB (2007) Coupled biological and physical models: present capabilities and necessary developments for future studies of population connectivity. Oceanography 20:54-70

Yu NH (2002) New challenges: breeding species in Taiwan, VIII. Fish Breeding Association of the Republic of China, Kaohsiung. Available at: www.fish.org.tw/english/intro.htm

Zar JH (ed) (1996) Biostatistical analysis, 3rd edn. Prentice Hall, Upper Saddle River, NJ

Submitted: November 5, 2008; Accepted: December 29, 2008 Proofs received from author(s): March 16, 2009 